\title{
Reference Point Formation - Does the Market Whisper in the Background?
}

Tianyang Wang

Department of Finance and Real Estate

Colorado State University

Fort Collins, CO 80523-1272

Tel: (970) 491-2381

tianyang.wang@colostate.edu

Sriram V. Villupuram

Department of Finance

University of Texas-Arlington

Tel: (817) 272-3705

sriramv@exchange.uta.edu

Robert G. Schwebach

Department of Finance and Real Estate

Colorado State University

Fort Collins, CO 80523-1272

Tel: (970) 491-5547

rob.schwebach@colostate.edu 


\title{
Reference Point Formation - Does the Market Whisper in the Background?
}

\begin{abstract}
Experimental studies in behavioral finance historically have confirmed that subjects are highly influenced by reference points when making economic decisions. A recent study by Baucells, Weber and Welfens (2011) analyzed the dynamics of reference price formation using experimental methods with subjects forming reference prices for stocks based on observed price sequences. Their study helps to clarify behavioral effects of past prices on reference price formation but it does not consider contextual information. We extend the BWW study by adding market price information as background to the experiment, and we investigate how this additional information affects reference point formation and updating. Our overarching hypothesis is that if the market background information has no impact then it should not alter the results of BWW; otherwise, the additional market information should be an explanatory variable for the reference point. Our results confirm the hypothesis that market information matters. We also investigate the impact of pessimism and optimism on reference prices by the combining the BWW framework with a model of disappointment aversion and anticipatory feelings developed by Gollier and Muerman (2010). Our study fills a void in the literature by providing new evidence on the impact of contextual market information on reference point formation in an investment setting.
\end{abstract}

Keywords: behavioral finance; reference-point formation; reference-dependent preferences 


\section{Reference Point Formation - Does the Market Whisper in the Background?}

\section{Introduction}

A common assumption in behavioral finance is that individuals measure gains and losses relative to a subjective reference point. This assumption underlies Kahneman and Tversky's (1979) prospect theory which posits that perceived value derives not only from absolute wealth but also from changes in wealth. This is in contrast to standard expected utility (EU) theory [von Neumann and Morgenstern (1947), Savage (1954)] which assumes that utility is based solely on final wealth. Reference points may shift over time in response to price changes and other factors, reflecting the phenomenon that decision makers habituate to new wealth levels just as individuals adapt their sensory perceptions to physical changes in brightness or temperature. In investment settings, a shift in the reference point toward a newly realized price is called adaptation. In multi-period settings, adaptation is a dynamic process and the reference point is often viewed as some function of current and past prices.

Because reference prices play a critical role in behavioral finance, researchers are interested in understanding the processes by which reference prices form and evolve. Previous work by Baucells, Weber and Welfens (2011; hereafter BWW) analyzes reference price dynamics in an experimental setting in which subjects formulate reference prices for hypothetical stocks based on simulated price patterns presented on a computer screen. BWW assumed that investor preferences follow a rank-dependent [Tversky and Kahneman (1992)] type of prospect theory value function. Rank-dependent models are one of two main classes of non-EU models of investor choice in the behavioral finance literature. The other main class consists of disappointment aversion models [Bell (1985), Gul (1992)].

We extend the work of BWW by adding market price information as background to the experiment, and we investigate how this contextual information affects reference point dynamics. We use an expanded framework that considers both prospect theory prospect theory and disappointment theory explanations of reference point formation. To represent the latter type we use Gollier and Muerman’s (2010; hereafter GM) model of ex ante savoring and ex post disappointment that combines Bell’s (1985) disappointment theory with Akerlof and Dickens' (1982) concept of anticipatory feelings. This over-arching framework adds additional clarity to BWW's original findings and provides a decomposition of their results based on stockand market-related factors.

\section{Background and Motivation}

Prospect theory differs from standard EU theory in that it assumes an S-shaped value function that is concave over gains and convex over losses. This implies diminishing marginal value away from the origin, 
resulting in decision behavior that is risk averse in the gain region and risk seeking in the loss region. prospect theory and the related concept of mental accounting [Thaler (1985)] help to explain empirical violations of EU such as the disposition effect [Shefrin and Statman (1985)] which states that investors tend to dispose of gains quickly but resist selling at a loss. The disposition effect implies that reference point adaptation will be more complete for an increase in price from an assumed reference point versus a decrease of equal magnitude. A stream of research over several decades, including BWW, provides empirical [e.g., Odean (1998)] and experimental [e.g., Weber and Camerer (1998)] support for prospect theory explanations of the disposition effect in investment settings.

In addition to the convexity assumption, prospect theory postulates that the S-shaped value function is steeper in the loss region so that losses are felt more intensely than gains. This feature results in loss aversion or the reluctance to realize losses. Loss aversion leads investors to choose loss avoidance over the possibility of earning gains of similar magnitude. Loss avoidance may induce price-barrier effects where investors are unwilling to adapt their reference price below a level that would result in a perceived loss. A related notion of anchoring [Tversky and Kahneman (1974] refers to the heuristic bias for reference points to gravitate toward irrelevant or noninformative values. For example, in real estate a seller might anchor to the first offer presented in a negotiation process.

Prospect theory and mental accounting reflect the hedonic aspects of maximizing psychological pleasure and minimizing psychological pain. This is manifest in two ways. Kahneman (1994) distinguishes between decision utility as measured by the S-shaped value function versus experienced utility which refers to immediate psychological feelings of pleasure or pain associated with economic decisions. Decision utility is prospective and relates to the curvature of the value function. Concavity over gain regions motivates investors to close out their mental account (i.e., adapt to the new price level) when in the black because it resets the value function to zero so that future gains will be more intense. On the other hand, convexity over loss regions has the opposite effect and leads investors to keep their mental accounts open when in the red so as to lessen the intensity of future losses. In contrast to decision utility, experienced utility refers to the immediate emotional consequence of closing out one's mental account. It motivates investors to close out their mental account when in the black (immediate gratification) and dissuades them from doing so in the red (immediate misery). Both types of utility affect reference point adaptation in ways consistent with the disposition effect [see Arkes et al. (2008)].

While prospect theory has largely been supported empirically, research has shown that some of its key results are unstable across different contexts or framing domains [Hershey and Shoemaker (1980), Fischhoff (1983), Schneider and Lopes (1986)]. In addition, several studies document alternative explanations for the disposition effect such as portfolio rebalancing [Samuelson (1969), Merton (1969)], selective attention [Barber and Odean (2007), Karlsson, Loewenstein and Seppi (2009)], irrational beliefs 
about mean reversion [Barber and Odean (1999), Barberis and Xiong (2012)], and anticipatory feelings of regret [Bell, (1982), Loomes and Sudgen (1982)] or disappointment [Bell (1985), Gul (1991)]. The latter category includes as a variation the GM model of disappointment aversion and anticipatory feelings. All of these findings suggest that reference point effects are context-dependent. This limits generalizabilty and complicates the task of sorting out the interplay between inherent and context-driven effects, highlighting the need for more work in this area. Toward that end, we incorporate market information into the BWW framework to develop a new platform for analyzing the impact of market context on reference price formation. Our model combines BWW and GM into an over-arching framework that accommodates both prospect theory and disappointment theory explanations of reference point effects.

There are several reasons why market context might affect the reference point dynamics of individual stocks. Covariation between markets and individual stocks may lead investors to base reference point decisions on the current market state in combination with covariation measures such as beta, correlation or co-skewness. Recent studies have documented context-specific effects that vary by market condition. Lee et al. (2013) reports that investors with extreme capital losses are more active in redeeming mutual fund shares in a bear market than a bull market, whereas investors with moderate capital gains are less active in redeeming fund shares under a bull market. In neutral markets, they found that investors redeem both winner and loser funds except when they have extreme capital losses. Karlsson et al. (1985) concludes that adaptation is faster in rising markets than falling markets because investors pay more attention in rising markets. However, Arkes et al. (2008) finds that adaption to gains is greater than adaptation to losses whether the market is up or down, suggesting that attention is not the only factor. Kliger and Kudryavstev (2008) find that reference point adaptation is more reactive when stocks are more sensitive to market fluctuations, i.e., for high beta stocks.

\section{Methodology}

A primary way that behavior-based models differ from EU is through the assumption of probabilitydependent preferences (PDPs), where perceived utility depends not only on the shape of the utility function but also on subjective decision weights that may differ from objective probabilities. Fehr-Duda and Epper (2015) identify two main classes of PDP models: rank-dependent models [Quiggin (1982), Tversky and Kahneman (1992)] which include cumulative prospect theory as a variant; and disappointment aversion models [Gul (1991)]. These two general types are differentiated by the manner in which subjective decision weights are formed. In rank-dependent models such as BWW, decision weights are based on a ranking of possible outcomes and gains and losses are measured relative to an exogenous reference point. In disappointment aversion models, decision weights and the reference point are determined endogenously so as to optimally balance a tradeoff between feelings of anticipation and disappointment. We investigate 
market context-related effects under each of these two broad frameworks.

\subsection{Theoretical Motivation and Experimental Framework}

Our experimental framework is similar to BWW who presented subjects with scenarios portraying a hypothetical sequence of stock prices $y_{1}, \ldots, y_{n}$. For each observed price sequence, they elicited a reference price $\hat{y}_{n+1}$ from the subject. From these reference points, they inferred decision weightings on beginning, ending, and intermediate prices of the sequence for a representative subject.

BWW considered two possible mechanisms of reference point formation to describe how subjects arrive at their reported values of $\hat{y}_{n+1}$. Under the integrated mechanism, past prices are aggregated into a single reference value, $r_{n+1}=f\left(y_{1}, \ldots, y_{n}\right)$, and experienced utility at time $n+1$ is determined by comparison of this reference value to the price at time $n+1$. The subject's reported value $\hat{y}_{n+1}$ solves $v\left(\hat{y}_{n+1}-r_{n+1}\right)=0$, where $v$ is a prospect theory value function such that $v(0)$ represents emotional neutrality. In other words, the reported value $\hat{y}_{n+1}$ is the subject's unique reference price. Under the segregated mechanism, the value function is applied separately to each past price, and overall utility is taken as a weighted average of the separate utility measures: $\sum_{i=1}^{n} \bar{\pi}_{n, i} v\left(y_{n+1}-y_{i}\right)$, where the weights sum to 1 . The reported reference price $\hat{y}_{n+1}$ solves: $\sum_{i=1}^{n} \bar{\pi}_{n, i} v\left(\widehat{y}_{n+1}-y_{i}\right)=0$. The weights do not represent probabilities but are "prevalences" that measure subjective importance to the subject of each price in the sequence. For example, if only the purchase price matters then $\bar{\pi}_{n, 1}=1$ and all of the other weights are zero. BWW find that initial and ending prices are heavily weighted, indicating high salience, and that intermediate prices receive less decision weight.

Rank-dependent models can help to explain apparent anomalies such as the disposition effect but they generally do not necessarily specify an underlying behavior mechanism for the subjective weighting. The GM model explicitly postulates a behavioral process for the formation of decision weights based on feelings of anticipated disappointment and ex ante savoring. These feelings correspond to the human traits of pessimism and optimism which are perhaps the most common characterizations of market sentiment. Hence, the disappointment aversion model is a natural choice for analyzing the impact of market context on reference point formation.

The GM model assumes a set of lottery payoffs $\left\{c_{1}, \ldots, c_{S}\right\}$ with corresponding objective probabilities $Q=\left\{q_{1}, \ldots, q_{S}\right\}$. The decision agent forms an anticipated payoff $y$ that provides satisfaction from ex ante savoring but at the same time increases ex post disappointment. The agent chooses subjective probabilities $P=\left\{p_{1}, \ldots, p_{S}\right\}$ simultaneously with $y$ so as to optimally balance the utility tradeoff between savoring and disappointment. The reference point is the optimal value $y^{*}$ that equates the expected payoff to the certainty-equivalent of the risky lottery. GM express this as a maximization problem over an intertemporal 
preference functional $W(Q)$ that is a weighted sum of anticipatory satisfaction at Date 1 and expected satisfaction from the final payoff at Date 2:

$$
\begin{gathered}
W(Q)=\max _{P, y} k \sum_{S=1}^{S} p_{s} U\left(c_{s}, y\right)+\sum_{s=1}^{S} q_{s} U\left(c_{s}, y\right) \\
\text { s.t. } U(y, y)=\sum_{S=1}^{S} p_{s} U\left(c_{s}, y\right)
\end{gathered}
$$

The first term measures ex ante utility from anticipatory savoring based on subjective probabilities $P$, whereas the second term computes utility of ex post consumption based on objective probabilities $Q$. The certainty-equivalence condition is imposed by the constraint, and parameter $k$ is an intensity measure of the agent's anticipatory feelings.

In our expanded framework, the relevant connection between BWW and GM is through the role of information. In GM, at any time prior to the resolution of uncertainty, decision makers can re-optimize their utility in response to new information by forming a new combination of reference price $y^{*}$ and subjective probabilities $P^{*}$. Consider a thought experiment where a GM decision agent forms a reference price based on past stock price information, as in BWW. Prior to resolution of uncertainty, new information arrives that changes the decision agent's outlook, making her either more optimistic or more pessimistic. The agent can reassess the situation and recalibrate her probabilities to form a new reference price and achieve a new level of utility, which may be either higher or lower than before, but one that is optimal given the new information. The resulting change in the reference price represents the marginal impact of the new information. We designed our experiment with the aim of capturing such incremental effects, where the information in this case is market context. Our overarching hypothesis is that market context matters, which we are able to demonstrate by conditioning BWW's results on different market states.

Note that the change in perceived utility requires no action on the part of the agent. However, it does require the agent to deliberately balance 'wishful thinking' with realistic expectations in a way that, as GM point out, involves managing some cognitive dissonance. However this is something humans do all the time in order to feel better about situations they may not control. New information may provide a signal that triggers a rebalancing of the tradeoff between apprehension and elation. You may contemplate this tradeoff even if you don't act on it. Such contemplation, whether subconscious or volitional, is equivalent to changing the amount that you would be willing to pay if you imagined placing a hypothetical bet, i.e., it is equivalent to changing your reference point.

\subsection{Experiment Design}

Experiments were conducted in a classroom setting at Colorado State University on groups of subjects consisting of male and female undergraduate finance students who had completed at least one junior-level principles of finance course. Subjects completed the experiment individually on personal computers. 
Separate group sessions were held on three different dates and results were combined. The combined sample size was 63 students after eliminating outliers and obvious data entry errors. Room conditions were similar for each session and we did not separate results according to which session students attended.

Following BWW, we presented each subject with a series of simulated stock price patterns on a computer screen. For each pattern we asked the subject to imagine that they purchased the stock several days ago and then immediately went on vacation to a locale where they could not trade or monitor its price. Upon returning from vacation, the subject views a sequence of stock prices that occurred during their absence. Similar to Arkes et al. (2008) and BWW, we elicit a reference point by asking the subject to enter a price that would produce 'emotional neutrality' if they were to sell the stock at their stated price. For comparability with BWW we used essentially the same language in our instructions to the subject. Unlike BWW, however, in addition to the stock pattern we also displayed a simultaneous price pattern for the overall stock market, to which students were free to either pay attention or ignore. We made no mention of the market information either verbally or in writing to avoid introducing semantic or framing effects; we simply added the market price sequence as subtle background information, giving no explanation or clarification as to its relevance. The exact set of instructions that we gave to subjects appears in Exhibit A.

\section{[Insert Exhibit A Here ]}

For each stock price path, we are interested in the extent of reference point adaptation, i.e., the degree to which a subject's reference point tends toward the most recently observed stock price. Adaptation is measured as a proportion of the cumulative observed stock price change as follows:

$$
A_{i}=\frac{R_{i}-P P}{C P-P P}
$$

where $i$ denotes the $i$ th subject, and where $P P$ and $C P$ denote the stock's purchase price and current price, respectively. An illustration of adaptation levels for two illustrative simple stock patterns appears in Figure 1. Panel $a$ represents a capital loss situation $(C P<P P)$, and panel $b$ represents a capital gain $(C P>P P)$. Complete adaptation is defined as $A_{i}=1$, implying a reference price of $R_{i}=C P$, whereas zero adaptation implies $A_{i}=0$ and $R_{i}=P P$. Reference price adaptation can exceed $1\left(R_{i}>C P\right)$ or be negative $\left(R_{i}<P P\right)$. For example, if a stock is purchased at $\$ 200$ and ends at $\$ 250$, a reference price of $\$ 275$ implies overadaptation with $A_{i}=1.5$, and a reference price of $\$ 175$ implies negative adaptation with $A_{i}=-0.5$.

\section{[Insert Figure 1 Here]}

BWW devised a methodology to measure the impact of various price factors on subjects' reference points by constructing 'orthogonal' pairs of price sequences to isolate the effects of individual factors. Specifically, BWW focused on the following five factors: purchase price $(P P)$; current price $(C P)$; average intermediate price $(A I P)$; highest price $(H P)$; and lowest price $(L P)$. BWW formed orthogonal pairs such 
that each pair of price sequences was identical with respect to exactly four factors; hence any difference between the reference points from those two sequences must be attributable to the fifth factor.

We extend BWW's methodology by associating each stock price pattern with four market price paths that can be strategically paired to analyze interaction effects between stock and market factors. Specifically, we first selected a subset of 20 BWW stock price patterns, then we augmented each stock pattern by constructing four associated market patterns, creating four sub-cases labeled $a-d$ for each original stock pattern. This resulted in 80 total cases where each case consists of a stock pattern and an associated market pattern, for a total of 160 stock and market price patterns. We contrived our market patterns in a manner to facilitate analysis of both stock and market characteristics, as well as covariation effects. A complete listing of our stock and market patterns appears in Table 1. To be consistent with BWW we kept the same numbering of stock patterns; therefore, as we only used a subset of patterns there are gaps in our numbering.

[Insert Table 1 Here]

\section{Analysis and Results}

Each of the 63 subjects reported reference prices for 80 unique stock/market price patterns, resulting in 5,040 reference point observations that we analyzed a number of different ways. The average reported reference price for all 63 subjects for each pattern appears in the last column of Table 1.

\subsection{Impact of Market Context on Reference Point Formation}

The stock and corresponding market price patterns were devised to systematically analyze interactions between stock and market effects on reference price behavior. For instance, Figure 2 displays an example involving stock price patterns 1 and 2 from Table 1 , which are denoted by $j$ and $k$, respectively.

[Insert Figure 2 Here]

In each panel, stock patterns $j$ and $k$ are identical with respect to all factors except purchase price; therefore any difference in the reference prices, $R_{j}-R_{k}$, must be attributable to the purchase price. In panel $a$, the average reference prices differ by 33.05 and the purchase price differs by 100; therefore the unit increase in reference price for each dollar of price differential is 0.33 , other factors held constant. Note the market price in panel $a$ follows a down-up pattern. Panel $b$ is identical except that its market pattern is updown. The unit effect in panel $b$ is 0.44 which is one-third higher than panel $a$, showing that stock price adaptation can be influenced by subtly displayed differences in market background.

Each panel in Figure 2 measures the unit impact of purchase price on the reference point under a different market scenario. In all, of the 80 unique stock/market patterns, eight different orthogonal pairs can be formed to similarly measure the unit impact of $P P$ under different market scenarios. These eight patterns 
are shown in Table 2, along with similar sets of eight orthogonal pairs that were formed to measure the impact of each of the other stock price factors, $C P, A I P, H P$ and $L P$ under various market contexts. This table shows the eight pairings used to isolate each factor, and displays the reference price differential that was observed on average, both in dollar terms and per currency unit. For a given stock price factor, different reference price differentials are observed for different orthogonal pairs, indicating that the impact of the price factor depends on market context.

\section{[ insert Table 2 approximately here ]}

For each pairing, we performed a matched-pair sign test, similarly to BWW, to test the significance of results for each row in the table; $p$-values appear in the last column of Table 2 . For $P P$ and $C P$, the $p$-values indicate uniformly strong statistical significance, with mixed results obtained for the other factors. Table 2 results are summarized below.

- Purchase price: We find an overall average unit effect of 0.38 for $P P$, with substantial differences observed across market patterns. For example, the four cases comparing stock patterns 1-2 produced unit effects ranging from 0.33 to 0.44 , conditioned on the market pattern. For stock patterns 7-8 the conditional unit effects ranged from 0.28 to 0.45 , suggesting that market context matters. Our findings for $P P$ are uniformly significant, with $p$-values of zero for all eight cases.

- Current price: For $C P$, the overall average unit effect is 0.42 . Similar to purchase price, we observe considerable variability observed across market scenarios and extremely high statistical significance for all eight cases. Notably, stock patterns 11-12 exhibit unit effects ranging from 0.41 to 0.61 , while stock patterns 15-16 exhibit less variable unit effects ranging from 0.31 to 0.37 .

- Average intermediate price: For AIP, the overall average unit effect is 0.12. Again, the conditional effect exhibits wide variation; however only about half of the cases are statistically significant. Overall, these results suggest a relatively weak influence of $A I P$ compared to $P P$ and $C P$, with market information having less of an influence on reference price formation compared to the previous factors.

- High price: We find this factor to be largely non-influential. The overall average unit effect is only 0.04, and most of the orthogonal pairs involving HP are not statistically significant.

- Low price: LP exhibits an overall average unit effect of -0.22. Notably, patterns 35-36 indicate highly influential and significant results with wide variation across market patterns. The conditional unit effects range from -0.30 to -0.57 , all with $p$-values of zero. These results suggest that investors might sometimes anchor to the stock's historical low price, depending on the market situation.

The average effect across eight orthogonal pairs for each price factor represents a cross-section of 
different combinations of stock and market scenarios, and can be compared to the unconditional impact measured by BWW who did not include information in the experiment. When taken overall, our results are remarkably consistent with BWW for most of the stock price factors. Notably, our overall average unit effect across all scenarios for all five factors combined is equal to 0.74 , compared to an overall average of 0.75 for BWW. Our results serve to decompose BWW's unconditional measures to provide a more nuanced explanation of reference point dynamics, which we explore further with additional analysis below.

\subsection{Regression Analysis}

Following BWW, we analyzed the impact of relevant factors by performing a regression of the reference prices reported by subjects on relevant factors in a combined model containing data from all of the paired comparisons. Whereas BWW considered only the five stock-related factors discussed above, we include market-related factors as additional independent variables. Results appear in Table 3. For comparison

purposes, we include BWW's findings in our results table. As in BWW, standard errors are clustered by subject to remove correlation bias.

\section{[Insert Table 3 Here]}

In Table 3, we first performed a 'naïve' regression (model 1) using the same five stock-related factors used by BWW. In comparing our results to BWW, we note that BWW obtained significance for all five stock-related factors, whereas we obtained significance for only three factors, namely purchase price, current price and, to a much lesser extent, lowest price. This difference in results can be explained by the fact that our subjects used additional market information to form their reference prices, which is omitted from the set of independent variables, whereas BWW used only stock price information for form their reference prices. Our intercept of 57.53 is significantly higher than BWW's intercept of 15.20. Our intercept is higher because it absorbs the missing explanatory power associated with omitted market-related factors. BWW attributed their intercept to the possibility that subjects may be adding in a built-in profit, which is a viable interpretation for both models. In model 1 our coefficients on $P P$ and $C P$ are 0.38 and 0.43 , respectively.

In model 2, we add five market-related information in the form of price factors $P_{m k t}, C P_{m k t}, A I P_{m k t}$, $H P_{m k t}$ and $L P_{m k t}$. Again, we find that the stock purchase price and current price are highly significant with coefficients of 0.37 and 0.45 , respectively. The high and low stock price are also significant but only slightly. In addition, the market's current price and average intermediate price are also highly significant with relatively small coefficients of 0.06 and -0.05 , respectively. The intercept is considerably lower than the previous model and is not significant. Apparently when market information is available, the investor still pays attention to the stock's current price and purchase price, but pays less attention to other stock- 
related variables, focusing instead on market factors such as current price and recent intermediate price trend.

In models 3 and 4 we add additional terms related to short-term and long-term price trends. In model 3 we add a factor called LASTLEG to capture the current short-term price trend as measured by the magnitude of price change observed since the most recent price reversal. In model 4 we add a factor called TREND to capture the long-term overall linear price trend, defined by the slope of a best-fit line computed for each price sequence plotted as a function of time using ordinary least squares. We add LASTLEG and TREND variables for both the stock and the market. We find that both of these terms are highly significant for the market, but for the stock sequence only mild significance is found for LASTLEG.

In models 5 and 6 we add measures of covariation, including BETA, defined as the slope of the characteristic line obtained by regressing the stock return on the market return using returns implied by each pair of stock and market price sequences, and a variable to represent tracking error, called TRACKERR, which measures how 'differently' the stock is moving compared to the market. TRACKERR is defined as the standard deviation of the difference between the stock and market return sequences. This measure is commonly used in practice in the mutual fund industry. In model 7, we added a term to capture interaction effects between BETA and LASTLEGmkt. In models 5-7 the results were mixed, however some statistical significance was found for the covariation factors as indicated in the table.

Overall, for the models we considered we found that the significance of market factors varied depending on which measures of trend and/or covariation were included. However, we found that the stock's purchase price and current price remained consistently significant across all model specifications with fairly stable coefficient values of approximately 0.37 for $P P$ stk and 0.45 for $C P$ stk. In addition to the regression models in table 3, we also examined models with various other factors, in numerous combinations, that we do not report.

\subsection{Interaction of Stock and Market Effects}

It is difficult to capture all of the relevant factors and their interaction effects in a single parsimonious model because the combined data set contains a wide range of different stock and market scenarios, whereas investor decision behavior is seldom the same across all market states and economic situations. To disentangle the stock and market effects we partition the data into subsets corresponding to different combinations of up/down price scenarios as shown in table 4 which we label as: $\mathrm{S} \uparrow \mathrm{M} \uparrow, \mathrm{S} \uparrow \mathrm{M} \downarrow, \mathrm{S} \downarrow \mathrm{M} \uparrow$ and $\mathrm{S} \downarrow \mathrm{M} \downarrow$. This partitioning automatically segregates the interaction effects without requiring a model specification involving a large number of complex interaction terms.

[Insert Table 4 Here] 
We consider two different definitions of what constitutes an up or down price state. In panel $a$ we define both stock and market states in terms of capital gains and losses computed as $(C P-P P)$; in panel $b$ we define both stock and market states in terms of the linear TREND variable; and in panel $c$ we use $(C P-P P)$ for stocks and TREND for the market. In each panel we examine two model specifications. Model 1 consists of the five stock factors used by BWW. Model 2 is a reduced model obtained from a backward stepwise regression. All of the models in table 4 cluster standard errors by subject to remove correlation bias.

Table 4 reveals consistent patterns that corroborate well known reference price effects. First, we observe that in three of the four states (all except $\mathrm{S} \downarrow \mathrm{M} \uparrow$ ), investors seem to focus more on $C P$ relative to $P P$, indicating a relatively higher degree of adaptation in those states. It is most pronounced in states where the stock and market move in the same direction, and it holds whether the price direction is measured by capital gains or by linear trend. This suggests that investors adapt more completely when the stock and the market are moving in the same direction. When the stock and market move in opposite directions, we observe that investors focus more on $P P$ when $\mathrm{S} \downarrow \mathrm{M} \uparrow$ indicating less complete adaptation; but they focus more on $C P$ when $\mathrm{S} \uparrow \mathrm{M} \downarrow$ indicating more complete adaptation. Taken together, these results corroborate a disposition effect, but only in up market scenarios. This is consistent with the attention hypothesis of Karlsson et al. (1985), who posit that the disposition effect occurs because investors pay relatively more attention in rising markets.

In the loss domain, we find that investors focus on $P P$ if the market is up, but they focus on $C P$ if the market is down. It appears that the market price exerts a 'pull' on the reference price, moving the reference price in the same direction as the market. Intuitively, when $\mathrm{S} \downarrow \mathrm{M} \downarrow$ the market pulls the reference price lower, i.e., in the direction of the current price (because $P P>C P$ ). Perhaps the falling market leads investors to contemplate abandoning their loss before it falls even further into loss territory, which leads to more complete adaptation as they anchor to the current price. But when $\mathrm{S} \downarrow \mathrm{M} \uparrow$, the market pulls the reference price higher, moving it in the same direction as $P P$. Perhaps the rising market encourages investors to hold onto the stock and wait for it to go back up, which leads to less complete adaptation as they anchor to the purchase price.

We also observe that when the stock and the market move in the same direction, the coefficient of $L P$ is negative and highly significant. This is consistent with the downside risk hypothesis of Ang et al. (2006) which suggests that investors focus more on downside risk when stocks are highly correlated with the market.

\section{Graphical Depiction}


To gain additional intuition and further sort out patterns of stock and market influences on reference prices, we provide graphical analysis of our results in Figures 3-7. These graphs provide deeper insight and aid in visualizing stock and market interaction effects in a convenient and novel manner.

\subsection{Reference Point Adaptation in Gain versus Loss Domain}

The extent of adaptation for a given individual may depend on intermediate stock and market price movements, and such factors may affect different individuals in different ways. However, the same individual may exhibit patterns of consistent behavior according to the market state and/or based on whether the stock is in a capital gain $(C P>P P)$ or capital loss $(C P<P P)$ position. We say that an individual exhibits the disposition effect if that individual's mean adaptation in gain scenarios exceeds the individual's mean adaptation in loss scenarios. In Figure 3 we analyze within-subject behavior by plotting each individual's combination of mean adaptation in loss versus gain scenarios as an $(x, y)$ ordered pair. For example, the ordered pair $(0.40,0.80)$ would depict an individual who averages 40 percent adaptation when sitting on capital losses and 80 percent adaptation when sitting on capital gains. Each subject is represented by a point in the scatter plot. There are 63 data points corresponding to the number of subjects in the experiment. An individual who plots above the $45^{\circ}$ line in figure 1 exhibits the disposition effect. Separate graphs are shown for down-market scenarios (panel $a$ ) versus up-market scenarios (panel $b$ ), where up and down markets are defined by the sign of LASTLEGmkt. The box-shaped gridlines in Figure 3 delineate regions where $\left|A_{k}\right| \leq 0.5$ and where $\left|A_{k}\right| \leq 1.0$.

The results in Figure 3 indicate a strong disposition effect in both up and down markets, with a slightly stronger effect when the market trends upward. In up-market scenarios, 57 subjects (90\%) exhibit a disposition effect, versus 49 subjects (78\%) in down-market scenarios. A reverse disposition effect is observed for 6 subjects (10\%) in up-market scenarios and for 13 subjects (21\%) in down-market scenarios. In up-market scenarios the mean adaptation level averaged across individuals is $A_{k}=0.95$ in the gain domain, but only $A_{k}=0.13$ in the loss domain. In down-market scenarios the average adaptation across individuals is $A_{k}=0.82$ in the gain domain and $A_{k}=0.22$ in the loss domain.

\subsection{Reference Point Adaptation in Up versus Down Markets}

In Figure 4 we slice the data in a different manner and analyze within-subject behavior along the dimensions of up versus down markets, where up and down markets are defined by the sign of LASTLEGmkt. As before, each data point corresponds to a particular subject; however this time we define the $x$ - and $y$ axes to measure average adaptation in down versus up markets, as opposed to average adaptation in loss versus gain domains like we did in Figure 3. Separate graphs are shown for scenarios in the loss domain (panel $a$ ) versus the gain domain (panel $b$ ). The disposition effect is now discerned by differences between 
panels $a$ and $b$ as opposed to deviations from the $45^{\circ}$ line. The $45^{\circ}$ line is now interpreted as the case where investor behavior is identical in up and down markets, which corresponds to the BWW framework where subjects do not have market information. Therefore, departures from the $45^{\circ}$ line in Figure 4 represent the marginal effect of adding market information to the decision agent's information set.

Note that in the gain domain, positive adaptation implies an increase in the reference price, whereas in the loss domain positive adaptation implies a decrease in the reference price. This is because the denominator in equation (3) is negative in the loss domain and positive in the gain domain. In panel (b), an increase in the reference price corresponds to a rightward (in down markets) or upward (in up markets) shift of data points on the graph. But in panel (a), an increase in the reference price corresponds to a leftward (in down markets) or downward (in up markets) shift of data points on the graph. The gain and loss regions in the two panels are indicated by shading.

Figure 4 offers interesting insights. First, note that the inner box depicts individuals who adjust their reference point less than halfway, which indicates that they are focusing more on the purchase price than the current price. This happens mostly in the loss domain. Relatively few individuals in the gain domain exhibit this behavior. Second, note that points in the first quadrant represent individuals who systematically adapt positively in both up and down markets, and anything in the third quadrant represents individuals who systematically adapt negatively in both up and down markets. There is virtually no negative adaptation in the gain domain; but in the gain domain this would mean the reference point is lower than $P P$ even though the stock price has increased. There is some negative adaptation observed in the loss domain, for about 20 individuals. Intuitively, these individuals may be holding out for a selling price that is higher than what they originally paid $\left(R_{k}>P P\right)$.

The region outside of the inner box represents adaptation greater than 0.5 suggesting that an individual is focusing more on the current price than the purchase price. This happens frequently in the gain domain but infrequently in the loss domain, as would be expected as greater adaptation in the loss domain approaches capital loss territory with respect to the purchase price as adaptation approaches 1 . The region outside of the outer box represents adaptation greater than 1 which occurs frequently in the gain domain but is rarely observed in the loss domain. This is intuitive, as in the loss domain this would imply a capital loss relative to the purchase price. These types of observations are not evident from Table 3 because all up/down scenarios are lumped together, but these observations motivate the partitioning in Table 4.

In the gain domain, the data points in the first quadrant that lie outside the larger box represent overadaptation $\left(A_{k}>1\right)$ in both up and down markets. This encompasses about half of the individuals. But there are only a few such individuals in the loss domain. In the gain domain, more than complete adaptation means that $R_{k}>C P$, i.e., the subject's reservation price is above the current price whether the market is up 
or down. In the loss domain, it means that $R_{k}<C P$, i.e., the subject's reservation price is below the current price whether the market is up or down. As mentioned, this describes only a few individuals.

\subsection{Beta and Disappointment Aversion}

Next, in Figures 5 and 6 we consider the impact of disappointment aversion on reference point formation by considering how different economic states and asset covariation properties might affect investor optimism and pessimism. The GM model suggests that an increase in optimism should lead to higher reference prices, and an increase in pessimism should lead to lower reference prices. In Figures 5 and 6, panel $a$ outlines the predicted effects of beta and market direction on the level of optimism or pessimism about the stock in the gain domain and the loss domain, respectively.

Figure 5 hypothesizes that in the gain domain, negative beta stocks should plot lower and further right, whereas positive beta stocks should plot higher and further left. On the other hand, Figure 6 hypothesizes a tendency in the loss domain for negative beta stocks to plot higher and further left, and for positive beta stocks to plot lower and further right. Note there is an asymmetry in the loss domain due to the fact that in the loss domain, the signs of $A_{k}$ and $\mathrm{R}_{k}$ are inversely related.

In panel $b$ of Figures 5 and 6 we partition the data based on the sign of beta, into top tercile (positive beta) and bottom tercile (negative beta), where terciles are determined by cutoff values of +1.15 and -1.15 . We test our hypothesis informally by visual inspection by comparing the slopes and intercepts of the characteristic lines for positive and negative beta partitions.

The graphs in panel $b$ of Figures 5 and 7 indicate some support for our hypotheses, but it is not uniform. In the loss domain, the characteristic line for negative beta stocks has a steeper slope compared to positive beta stocks, consistent with our prediction, but the intercepts are not significantly different. In the gain domain, negative beta stocks have a flatter slope which is consistent with our prediction, but negative beta stocks have a higher intercept which is opposite of our prediction.

In Figure 7 we plot the characteristic lines for different terciles on the same graph for comparison, including the middle tercile. Here we see that the graphs cross, and we observe that to the right of the crossover point the relative positioning of the graphs supports our hypothesis. Hence the predicted relationship appears to hold over most of the relevant range that contains most of the data points.

\section{Concluding Remarks}

This study develops an experimental framework for analyzing the effect of market context on reference point formation, synthesizing and extending previous studies by Baucells at al. (2011) and Gollier and Muerman (2010). The results support our overall hypothesis that market context matters. We analyze how reference point adaptation depends on the market state and asset covariation properties, and we develop a novel method of graphical portrayal that helps to visualize behavioral effects on reference point formation. 
While our study does not consider every possible factor that may influence reference point formation in different market states, we believe it is a step in that direction. We believe that our methodology provides a rich framework for analyzing reference price formation that it will be a useful platform for performing future research in this area. 


\section{REFERENCES}

Ackerlof, G. A. and W. T. Dickens. 1982. The economic consequenses of cognitive dissonance. American Economic Review. 72(3): 307-319.

Ang, A. Chen, J., Xing, Y. 2006. Downside risk. Review of Financial Studies. 19(4): 1191-1239.

Arkes, H. R., Hirshleifer, D., Jiang, D., \& Lim, S. S. (2008). Reference point adaptation: Tests in the domain of security trading. Organizational Behavior and Human Decision Processes. 105: 67-81.

Barber, B., Odean, T. 1999. The Courage of Misguided Convictions. Financial Analysts Journal. 55(6): 41-55

Barber, B., Odean, T. 2007. All That Glitters: The Effect of Attention and News on the Buying Behavior of Individual and Institutional Investors. The Review of Financial Studies. 21: 785-818.

Barberis, N. and Xiong, W. 2012. Realization utility. Journal of Financial Economics. 104: 251-271.

Baucells M., Weber, M., Welfens, F. 2011. Reference-Point Formation and Updating. Management Science. 57: 506-519.

Bell, D. 1982. Regret in decision making under uncertainty. Operations research. 30(5): 961-981.

Bell, D.E . 1985. Disappointment in Decision Making under Uncertainty. Operations Research. 33(1): 127.

Fehr-Duda, H., Epper, T. 2015. Probability and Risk: Foundations and Economic Implications of ProbabilityDependent Risk Preferences. Annal Review of Economics. 4: 567-93.

Fischhoff, B. 1983. Predicting Frames, Journal of Experimental Psychology: Learning, Memory and Cognition. 9: 103-116.

Gollier and Muerman. 2010. Optimal Choice and Beliefs with Ex Ante Savoring and Ex Post Disappointment. Management Science. 56(8):1272-1284.

Gul, F. 1991. A theory of disappointment aversion. Econometrica. 59: 667-86.

Hershey J., and J., Shoemaker. 1980. Prospect Theory’s Reflection Hypothesis: A Critical Examination, Organizational Behavior and Human Performance. 25: 395-418.

Kahneman, D., Tversky, A. 1979. Prospect Theory - Analysis Of Decision Under Risk. Econometrica. 47: 263-291.

Karlsson, N. Loewenstein, G., Seppi, D. 2009. The ostrich effect: Selective attention to information. Journal of Risk and Uncertainty. 38: 95-115.

Loomes, G., Sugden, R. 1986. Disappointment and dynamic consistency in choice under uncertainty. Review of Economic Studies. 53(2): 271-282.

Odean, T. 1998. Are investors reluctant to realize their losses? The Journal of Finance. 53: 1775-1798. 
Quiggin, J. (982. A theory of anticipated utility. Journal of Economic Behavior and Organization. 3: 323343.

Schneider, S. and L. Lopes. 1986. Reflection in Preferences Under Risk: Who and When May Suggest Why, Journal of Experimental Psychology: Learning, Memory and Cognition. 12: 535-548.

Shefrin, H., Statman, M. 1985. The disposition to sell winners too early and ride losers too long: Theory and evidence. The Journal of Finance. 40: 777-790.

Stracca, L. 2004. Behavioral Finance and Asset Prices: Where do we Stand? Journal of Economic Psychology. 25: 375-405.

Thaler, R. H. 1985. Mental accounting and consumer choice. Marketing Science. 4: 199-214.

Tversky, A., Kahneman, D. 1992. Advances in prospect theory: Cumulative representation of uncertainty. Journal of Risk and Uncertainty. 5: 297-323.

von Neumann, J and Morgenstern O 1947. Theory of Games and Economic Behavior. $2^{\text {nd }}$ Rev. Ed. Princeton University Press

Weber, M., Camerer, C. F. 1998. The Disposition Effect in Securities Trading: An Experimental Analysis. Journal of Economic Behavior \& Organization. 33: 167-184. 


\section{Exhibit A. Instructions for the Individual Choice Task}

Please consider the following situation: A few days ago, on day 0, you purchased a stock. However, on the same day you went on vacation. At your resort, you were able to monitor the price development of the stock and the market index but you could not trade it.

Today, the day before your return journey, you once again take a look at stock price development since your purchase on day 0 . Because you can trade the stock again the next day back home, you ask yourself how you would feel if you were going to sell the stock the next day. You ask yourself at what selling price you would feel neutral about the sale of the stock, i.e., be neither happy nor unhappy about the sale. You assume the stock price to rise or fall by up to $\$ 50$ every day and regard all possible price changes between $\$+50$ and $\$-50$ as equally likely.

On the following screens you will be confronted with several decision situations of this kind. You will be shown the stock price and market index development chart starting from the purchase on day 0 until the day before your return journey. The price for which you can trade the stock the next day back home is today still unknown. After the price sequence is plotted, you will be asked to indicate at which tomorrow's selling price you would just feel neutral regarding the sale. Hence, we want you to indicate the selling price at which you would have neither positive nor negative emotions about the sale of the stock, therefore being neither happy nor unhappy. You can choose the price for which you would feel exactly neutral by typing into the message box (see Figure). This task is not about your mathematical skills, and there is no right or wrong answer. Instead, we ask you to make a personal decision on a selling price that would neither make you happy nor unhappy about the sale of the stock.

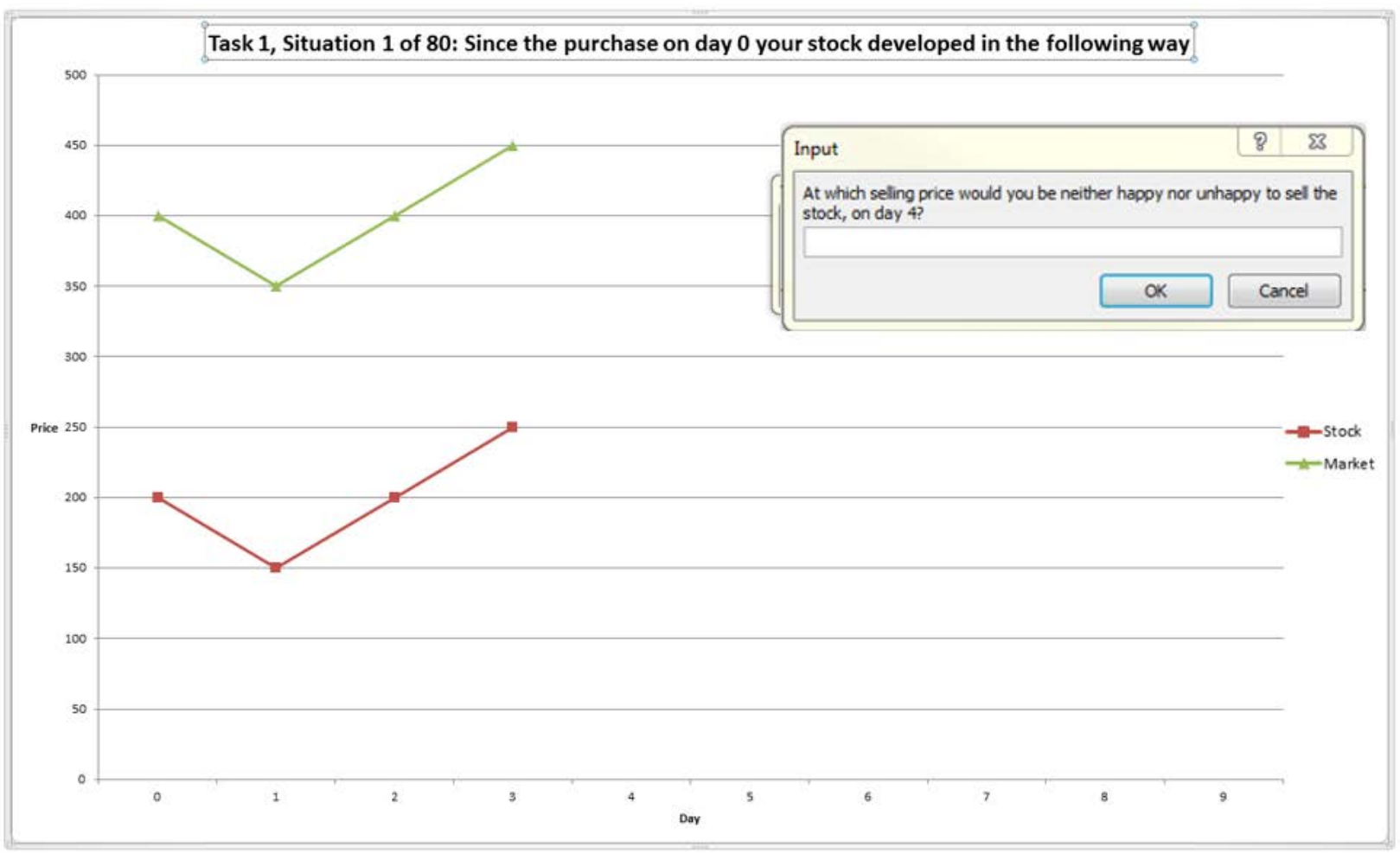




\begin{tabular}{|c|c|c|c|c|c|c|c|c|c|c|c|c|}
\hline Sequence & $k$ & Price Pattern & $\begin{array}{l}\text { Baucells } \\
\text { Stock } \\
\text { Number }\end{array}$ & $y_{1}$ & $y_{2}$ & $y_{3}$ & $y_{4}$ & $y_{5}$ & $y_{6}$ & $y_{7}$ & $y_{8}$ & Ave $R_{k}$ \\
\hline Stock & $1 a$ & & 1 & 250 & 200 & 150 & 200 & & & & & 239.1 \\
\hline Market & $1 a$ & & 1 & 400 & 350 & 300 & 350 & & & & & \\
\hline Stock & $1 \mathrm{~b}$ & & 1 & 250 & 200 & 150 & 200 & & & & & 238.4 \\
\hline Market & $1 \mathrm{~b}$ & & 1 & 400 & 450 & 500 & 450 & & & & & \\
\hline Stock & $1 \mathrm{c}$ & & 1 & 250 & 200 & 150 & 200 & & & & & 242.3 \\
\hline Market & $1 \mathrm{c}$ & & 1 & 400 & 350 & 300 & 450 & & & & & \\
\hline Stock & $1 d$ & & 1 & 250 & 200 & 150 & 200 & & & & & 230.5 \\
\hline Market & $1 d$ & & 1 & 400 & 450 & 500 & 350 & & & & & \\
\hline Stock & $2 a$ & & 2 & 150 & 200 & 250 & 200 & & & & & 194.4 \\
\hline Market & $2 a$ & & 2 & 400 & 450 & 500 & 450 & & & & & \\
\hline Stock & $2 \mathrm{~b}$ & & 2 & 150 & 200 & 250 & 200 & & & & & 198.8 \\
\hline Market & $2 b$ & & 2 & 400 & 350 & 300 & 350 & & & & & \\
\hline Stock & $2 c$ & & 2 & 150 & 200 & 250 & 200 & & & & & 186.6 \\
\hline Market & $2 c$ & & 2 & 400 & 450 & 500 & 350 & & & & & \\
\hline Stock & $2 d$ & & 2 & 150 & 200 & 250 & 200 & & & & & 209.3 \\
\hline Market & $2 d$ & & 2 & 400 & 350 & 300 & 450 & & & & & \\
\hline Stock & $7 a$ & & 7 & 250 & 200 & 150 & 200 & 160 & 200 & 240 & 200 & 230.0 \\
\hline Market & $7 a$ & & 7 & 400 & 350 & 300 & 350 & 310 & 350 & 390 & 350 & \\
\hline Stock & $7 b$ & & 7 & 250 & 200 & 150 & 200 & 160 & 200 & 240 & 200 & 234.2 \\
\hline Market & $7 b$ & & 7 & 400 & 450 & 500 & 450 & 490 & 450 & 410 & 450 & \\
\hline Stock & $7 c$ & & 7 & 250 & 200 & 150 & 200 & 160 & 200 & 240 & 200 & 241.7 \\
\hline Market & $7 c$ & & 7 & 400 & 350 & 300 & 350 & 310 & 350 & 390 & 450 & \\
\hline Stock & $7 d$ & & 7 & 250 & 200 & 150 & 200 & 160 & 200 & 240 & 200 & 233.1 \\
\hline Market & $7 d$ & & 7 & 400 & 450 & 500 & 450 & 490 & 450 & 410 & 350 & \\
\hline Stock & $8 a$ & & 8 & 150 & 200 & 250 & 200 & 240 & 200 & 160 & 200 & 204.3 \\
\hline Market & $8 a$ & & 8 & 400 & 450 & 500 & 450 & 490 & 450 & 410 & 450 & \\
\hline Stock & $8 b$ & & 8 & 150 & 200 & 250 & 200 & 240 & 200 & 160 & 200 & 202.1 \\
\hline Market & $8 b$ & & 8 & 400 & 350 & 300 & 350 & 310 & 350 & 390 & 350 & \\
\hline Stock & $8 c$ & & 8 & 150 & 200 & 250 & 200 & 240 & 200 & 160 & 200 & 189.9 \\
\hline Market & $8 c$ & & 8 & 400 & 450 & 500 & 450 & 490 & 450 & 410 & 350 & \\
\hline Stock & $8 d$ & & 8 & 150 & 200 & 250 & 200 & 240 & 200 & 160 & 200 & 196.6 \\
\hline Market & $8 \mathrm{~d}$ & & 8 & 400 & 350 & 300 & 350 & 310 & 350 & 390 & 450 & \\
\hline Stock & $11 a$ & & 11 & 200 & 150 & 200 & 250 & & & & & 249.5 \\
\hline Market & $11 a$ & & 11 & 400 & 350 & 400 & 450 & & & & & \\
\hline Stock & $11 \mathrm{~b}$ & & 11 & 200 & 150 & 200 & 250 & & & & & 235.9 \\
\hline Market & $11 \mathrm{~b}$ & & 11 & 400 & 450 & 400 & 350 & & & & & \\
\hline Stock & $11 \mathrm{c}$ & & 11 & 200 & 150 & 200 & 250 & & & & & 237.5 \\
\hline Market & $11 \mathrm{c}$ & & 11 & 400 & 350 & 400 & 350 & & & & & \\
\hline Stock & $11 \mathrm{~d}$ & & 11 & 200 & 150 & 200 & 250 & & & & & 241.6 \\
\hline Market & $11 d$ & & 11 & 400 & 450 & 400 & 450 & & & & & \\
\hline Stock & $12 a$ & & 12 & 200 & 250 & 200 & 150 & & & & & 189.3 \\
\hline Market & $12 a$ & & 12 & 400 & 450 & 400 & 350 & & & & & \\
\hline Stock & $12 \mathrm{~b}$ & & 12 & 200 & 250 & 200 & 150 & & & & & 188.3 \\
\hline Market & $12 \mathrm{~b}$ & & 12 & 400 & 350 & 400 & 450 & & & & & \\
\hline Stock & $12 \mathrm{c}$ & & 12 & 200 & 250 & 200 & 150 & & & & & 200.7 \\
\hline Market & $12 \mathrm{c}$ & & 12 & 400 & 450 & 400 & 450 & & & & & \\
\hline Stock & $12 \mathrm{~d}$ & & 12 & 200 & 250 & 200 & 150 & & & & & 190.3 \\
\hline Market & $12 \mathrm{~d}$ & & 12 & 400 & 350 & 400 & 350 & & & & & \\
\hline Stock & $15 a$ & & 15 & 200 & 150 & 170 & 200 & 250 & 230 & & & 224.1 \\
\hline Market & $15 a$ & & 15 & 400 & 350 & 370 & 400 & 450 & 430 & & & \\
\hline Stock & $15 b$ & & 15 & 200 & 150 & 170 & 200 & 250 & 230 & & & 225.9 \\
\hline Market & $15 b$ & & 15 & 400 & 450 & 430 & 400 & 350 & 370 & & & \\
\hline Stock & $15 \mathrm{c}$ & & 15 & 200 & 150 & 170 & 200 & 250 & 230 & & & 223.1 \\
\hline Market & $15 \mathrm{c}$ & & 15 & 400 & 350 & 370 & 400 & 450 & 370 & & & \\
\hline Stock & $15 \mathrm{~d}$ & & 15 & 200 & 150 & 170 & 200 & 250 & 230 & & & 229.7 \\
\hline Market & $15 \mathrm{~d}$ & $\sim$ & 15 & 400 & 450 & 430 & 400 & 350 & 430 & & & \\
\hline
\end{tabular}




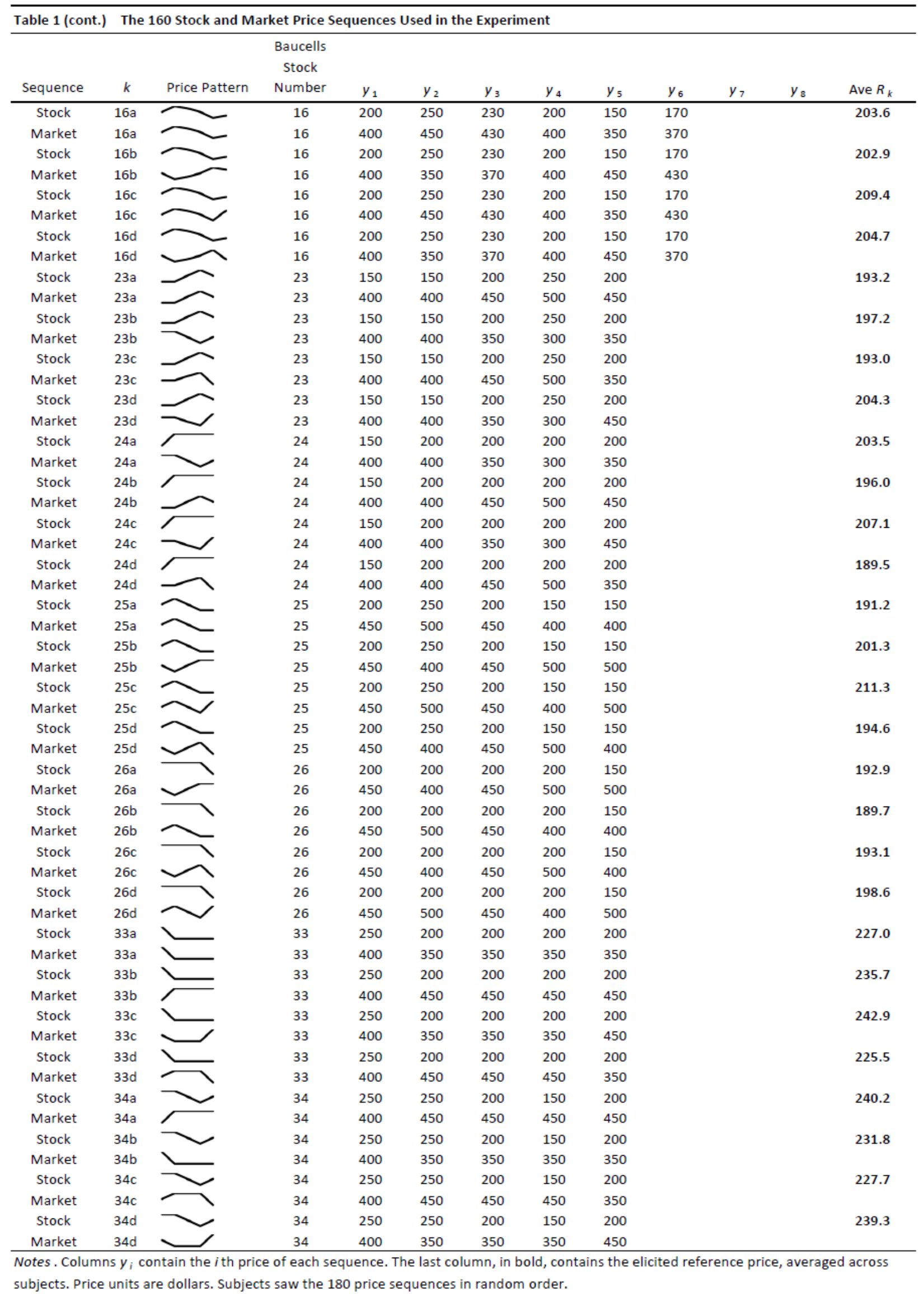


Table 1 (cont.) The 160 Stock and Market Price Sequences Used in the Experiment

\begin{tabular}{|c|c|c|c|c|c|c|c|c|c|c|c|c|}
\hline Sequence & $k$ & Price Pattern & $\begin{array}{l}\text { Baucells } \\
\text { Stock } \\
\text { Number }\end{array}$ & $y_{1}$ & $y_{2}$ & $y_{3}$ & $y_{4}$ & $y_{5}$ & $y_{6}$ & $y_{7}$ & $y_{8}$ & Ave $R_{k}$ \\
\hline Stock & $35 a$ & I & 35 & 200 & 200 & 200 & 200 & 250 & & & & 238.8 \\
\hline Market & $35 a$ & & 35 & 400 & 500 & 450 & 350 & 350 & & & & \\
\hline Stock & $35 b$ & 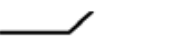 & 35 & 200 & 200 & 200 & 200 & 250 & & & & 240.7 \\
\hline Market & $35 b$ & & 35 & 400 & 300 & 350 & 450 & 450 & & & & \\
\hline Stock & $35 c$ & & 35 & 200 & 200 & 200 & 200 & 250 & & & & 228.5 \\
\hline Market & $35 c$ & & 35 & 400 & 500 & 350 & 450 & 450 & & & & \\
\hline Stock & $35 d$ & & 35 & 200 & 200 & 200 & 200 & 250 & & & & 234.9 \\
\hline Market & $35 d$ & & 35 & 400 & 300 & 350 & 450 & 350 & & & & \\
\hline Stock & $36 a$ & & 36 & 250 & 150 & 200 & 250 & 250 & & & & 255.8 \\
\hline Market & $36 a$ & & 36 & 400 & 300 & 350 & 450 & 450 & & & & \\
\hline Stock & $36 \mathrm{~b}$ & & 36 & 250 & 150 & 200 & 250 & 250 & & & & 255.6 \\
\hline Market & $36 \mathrm{~b}$ & & 36 & 400 & 500 & 450 & 350 & 350 & & & & \\
\hline Stock & $36 \mathrm{c}$ & & 36 & 250 & 150 & 200 & 250 & 250 & & & & 253.4 \\
\hline Market & $36 c$ & & 36 & 400 & 300 & 350 & 450 & 350 & & & & \\
\hline Stock & $36 \mathrm{~d}$ & & 36 & 250 & 150 & 200 & 250 & 250 & & & & 257.1 \\
\hline Market & $36 \mathrm{~d}$ & & 36 & 400 & 500 & 350 & 450 & 450 & & & & \\
\hline Stock & $45 a$ & & 45 & 200 & 150 & 200 & 250 & 250 & 250 & 250 & 200 & 213.5 \\
\hline Market & $45 a$ & & 45 & 400 & 350 & 400 & 450 & 450 & 450 & 450 & 350 & \\
\hline Stock & $45 b$ & & 45 & 200 & 150 & 200 & 250 & 250 & 250 & 250 & 200 & 222.0 \\
\hline Market & $45 b$ & & 45 & 400 & 450 & 400 & 350 & 350 & 350 & 350 & 450 & \\
\hline Stock & $45 c$ & & 45 & 200 & 150 & 200 & 250 & 250 & 250 & 250 & 200 & 219.7 \\
\hline Market & $45 c$ & & 45 & 400 & 350 & 400 & 450 & 450 & 450 & 450 & 450 & \\
\hline Stock & $45 \mathrm{~d}$ & & 45 & 200 & 150 & 200 & 250 & 250 & 250 & 250 & 200 & 221.7 \\
\hline Market & $45 \mathrm{~d}$ & & 45 & 400 & 450 & 400 & 350 & 350 & 350 & 350 & 350 & \\
\hline Stock & $46 a$ & & 46 & 200 & 250 & 200 & 150 & 150 & 150 & 150 & 200 & 221.9 \\
\hline Market & $46 a$ & & 46 & 400 & 450 & 400 & 350 & 350 & 350 & 350 & 450 & \\
\hline Stock & $46 \mathrm{~b}$ & & 46 & 200 & 250 & 200 & 150 & 150 & 150 & 150 & 200 & 213.5 \\
\hline Market & $46 \mathrm{~b}$ & & 46 & 400 & 350 & 400 & 450 & 450 & 450 & 450 & 350 & \\
\hline Stock & $46 c$ & & 46 & 200 & 250 & 200 & 150 & 150 & 150 & 150 & 200 & 207.5 \\
\hline Market & $46 c$ & & 46 & 400 & 450 & 400 & 350 & 350 & 350 & 350 & 350 & \\
\hline Stock & $46 d$ & & 46 & 200 & 250 & 200 & 150 & 150 & 150 & 150 & 200 & 212.9 \\
\hline Market & $46 d$ & & 46 & 400 & 350 & 400 & 450 & 450 & 450 & 450 & 450 & \\
\hline Stock & $47 a$ & & 47 & 200 & 250 & 250 & 250 & 250 & 200 & 150 & 200 & 218.4 \\
\hline Market & $47 a$ & & 47 & 400 & 450 & 450 & 450 & 450 & 400 & 350 & 450 & \\
\hline Stock & $47 \mathrm{~b}$ & & 47 & 200 & 250 & 250 & 250 & 250 & 200 & 150 & 200 & 223.8 \\
\hline Market & $47 \mathrm{~b}$ & & 47 & 400 & 350 & 350 & 350 & 350 & 400 & 450 & 350 & \\
\hline Stock & $47 c$ & & 47 & 200 & 250 & 250 & 250 & 250 & 200 & 150 & 200 & 218.2 \\
\hline Market & $47 c$ & & 47 & 400 & 450 & 450 & 450 & 450 & 400 & 350 & 350 & \\
\hline Stock & $47 d$ & & 47 & 200 & 250 & 250 & 250 & 250 & 200 & 150 & 200 & 217.8 \\
\hline Market & $47 d$ & & 47 & 400 & 350 & 350 & 350 & 350 & 400 & 450 & 450 & \\
\hline Stock & $48 a$ & & 48 & 200 & 150 & 150 & 150 & 150 & 200 & 250 & 200 & 206.1 \\
\hline Market & $48 a$ & & 48 & 400 & 350 & 350 & 350 & 350 & 400 & 450 & 350 & \\
\hline Stock & $48 \mathrm{~b}$ & & 48 & 200 & 150 & 150 & 150 & 150 & 200 & 250 & 200 & 217.3 \\
\hline Market & $48 \mathrm{~b}$ & & 48 & 400 & 450 & 450 & 450 & 450 & 400 & 350 & 450 & \\
\hline Stock & $48 \mathrm{c}$ & & 48 & 200 & 150 & 150 & 150 & 150 & 200 & 250 & 200 & 218.6 \\
\hline Market & $48 \mathrm{c}$ & & 48 & 400 & 350 & 350 & 350 & 350 & 400 & 450 & 450 & \\
\hline Stock & $48 \mathrm{~d}$ & & 48 & 200 & 150 & 150 & 150 & 150 & 200 & 250 & 200 & 211.1 \\
\hline Market & $48 \mathrm{~d}$ & - & 48 & 400 & 450 & 450 & 450 & 450 & 400 & 350 & 350 & \\
\hline
\end{tabular}




\begin{tabular}{|c|c|c|c|c|c|c|c|c|c|c|}
\hline PP & j & k & Ave. $R_{\mathrm{j}}$ & Ave. $R_{k}$ & $R_{j}-R_{k}$ & Unit Effect & $p$-value & stock j & stock $\mathrm{k}$ & market \\
\hline $1 a-2 b$ & 1a & $2 b$ & 239.08 & 198.81 & 40.27 & 0.40 & 0.00 & & & \\
\hline $1 b-2 a$ & $1 b$ & $2 a$ & 238.41 & 194.44 & 43.97 & 0.44 & 0.00 & & & \\
\hline $1 c-2 d$ & $1 c$ & $2 d$ & 242.35 & 209.30 & 33.05 & 0.33 & 0.00 & & & \\
\hline $1 d-2 c$ & $1 \mathrm{~d}$ & $2 c$ & 230.52 & 186.63 & 43.89 & 0.44 & 0.00 & & & \\
\hline $7 a-8 b$ & $7 a$ & $8 b$ & 230.03 & 202.13 & 27.90 & 0.28 & 0.00 & & & \\
\hline $7 b-8 a$ & $7 b$ & $8 a$ & 234.19 & 204.27 & 29.92 & 0.30 & 0.00 & & & \\
\hline $7 c-8 d$ & $7 c$ & $8 d$ & 241.75 & 196.63 & 45.11 & 0.45 & 0.00 & & & \\
\hline \multirow[t]{2}{*}{$7 d-8 c$} & $7 \mathrm{~d}$ & $8 c$ & 233.14 & 189.89 & 43.25 & 0.43 & 0.00 & & & \\
\hline & & & & & Ave: & 0.38 & & & & \\
\hline $\mathrm{CP}$ & $\mathrm{j}$ & k & Ave. $R_{j}$ & Ave. $R_{k}$ & $R_{j}-R_{k}$ & Unit Effect & $p$-value & stock j & stock k & market \\
\hline $11 a-12 b$ & $11 a$ & $12 \mathrm{~b}$ & 249.52 & 188.29 & 61.24 & 0.61 & 0.00 & & & \\
\hline $11 b-12 a$ & $11 \mathrm{~b}$ & $12 a$ & 235.94 & 189.35 & 46.59 & 0.47 & 0.00 & & & \\
\hline $11 c-12 d$ & $11 \mathrm{c}$ & $12 d$ & 237.46 & 190.25 & 47.21 & 0.47 & 0.00 & & & \\
\hline $11 d-12 c$ & $11 d$ & $12 \mathrm{c}$ & 241.60 & 200.71 & 40.89 & 0.41 & 0.00 & & & \\
\hline $15 a-16 b$ & $15 a$ & $16 \mathrm{~b}$ & 224.14 & 202.86 & 21.29 & 0.35 & 0.00 & & & \\
\hline $15 b-16 a$ & $15 b$ & $16 a$ & 225.90 & 203.59 & 22.32 & 0.37 & 0.00 & & & \\
\hline $15 c-16 d$ & $15 c$ & $16 \mathrm{~d}$ & 223.14 & 204.65 & 18.49 & 0.31 & 0.00 & & & \\
\hline \multirow[t]{2}{*}{$15 d-16 c$} & $15 \mathrm{~d}$ & $16 c$ & 229.75 & 209.41 & 20.33 & 0.34 & 0.00 & & & \\
\hline & & & & & Ave: & 0.42 & & & & \\
\hline AIP & $\mathrm{j}$ & k & Ave. $R_{j}$ & Ave. $R_{k}$ & $R_{j}-R_{k}$ & Unit Effect & $p$-value & stock j & tock k & arket \\
\hline $45 a-46 b$ & $45 a$ & $46 \mathrm{~b}$ & 213.46 & 213.54 & -0.08 & 0.00 & 0.09 & & & \\
\hline $45 b-46 a$ & $45 b$ & $46 a$ & 222.03 & 221.86 & 0.17 & 0.00 & 0.38 & & & \\
\hline $45 c-46 d$ & $45 c$ & $46 \mathrm{~d}$ & 219.75 & 212.94 & 6.81 & 0.14 & 0.02 & & & \\
\hline $45 d-46 c$ & $45 d$ & $46 c$ & 221.68 & 207.49 & 14.19 & 0.28 & 0.00 & & & \\
\hline $47 a-48 b$ & $47 a$ & $48 \mathrm{~b}$ & 218.44 & 217.33 & 1.11 & 0.02 & 0.26 & & & \\
\hline $47 b-48 a$ & $47 \mathrm{~b}$ & $48 a$ & 223.79 & 206.08 & 17.71 & 0.35 & 0.00 & & & \\
\hline $47 c-48 d$ & $47 c$ & $48 \mathrm{~d}$ & 218.16 & 211.13 & 7.03 & 0.14 & 0.00 & & & \\
\hline \multirow[t]{2}{*}{$47 d-48 c$} & $47 d$ & $48 c$ & 217.79 & 218.56 & -0.76 & -0.02 & 0.30 & & & \\
\hline & & & & & Ave: & 0.12 & & & & \\
\hline HP & j & k & Ave. $R_{\mathrm{j}}$ & Ave. $R_{k}$ & $R_{j}-R_{k}$ & Unit Effect & $p$-value & stock j & tock k & arket \\
\hline $23 a-24 b$ & $23 a$ & $24 b$ & 193.21 & 195.98 & -2.78 & -0.06 & 0.14 & & & \\
\hline $23 b-24 a$ & $23 b$ & $24 a$ & 197.24 & 203.52 & -6.28 & -0.13 & 0.02 & & & \\
\hline $23 c-24 d$ & $23 c$ & $24 d$ & 192.95 & 189.48 & 3.48 & 0.07 & 0.30 & & & \\
\hline $23 d-24 c$ & $23 d$ & $24 c$ & 204.27 & 207.10 & -2.83 & -0.06 & 0.12 & & & \\
\hline $25 a-26 b$ & $25 a$ & $26 \mathrm{~b}$ & 191.21 & 189.70 & 1.51 & 0.03 & 0.31 & & & \\
\hline $25 b-26 a$ & $25 b$ & $26 a$ & 201.35 & 192.94 & 8.41 & 0.17 & 0.09 & & & \\
\hline $25 c-26 d$ & $25 c$ & $26 \mathrm{~d}$ & 211.27 & 198.59 & 12.68 & 0.25 & 0.14 & & & \\
\hline \multirow[t]{2}{*}{$25 d-26 c$} & $25 \mathrm{~d}$ & $26 c$ & 194.56 & 193.14 & 1.41 & 0.03 & 0.29 & & & \\
\hline & & & & & Ave: & 0.04 & & & & \\
\hline LP & $\mathbf{j}$ & k & Ave. $R_{j}$ & Ave. $R_{k}$ & $R_{j}-R_{k}$ & Unit Effect & $p$-value & stock j & stock k & 1arket \\
\hline $33 a-34 b$ & 33a & $34 b$ & 226.97 & 231.76 & -4.79 & -0.10 & 0.17 & & & \\
\hline $33 b-34 a$ & $33 b$ & $34 a$ & 235.70 & 240.17 & -4.48 & -0.09 & 0.06 & & & \\
\hline $33 c-34 d$ & $33 c$ & $34 d$ & 242.87 & 239.35 & 3.52 & 0.07 & 0.08 & & & \\
\hline $33 d-34 c$ & $33 d$ & $34 c$ & 225.48 & 227.65 & -2.17 & -0.04 & 0.15 & & & \\
\hline $35 a-36 b$ & $35 a$ & $36 \mathrm{~b}$ & 238.84 & 255.62 & -16.78 & -0.34 & 0.00 & & & \\
\hline $35 b-36 a$ & $35 b$ & $36 a$ & 240.75 & 255.81 & -15.06 & -0.30 & 0.00 & & & \\
\hline $35 c-36 d$ & $35 c$ & $36 \mathrm{~d}$ & 228.52 & 257.06 & -28.54 & -0.57 & 0.00 & & & \\
\hline \multirow[t]{2}{*}{$35 d-36 c$} & $35 \mathrm{~d}$ & $36 c$ & 234.87 & 253.43 & -18.56 & -0.37 & 0.00 & & & \\
\hline & & & & & Ave: & -0.22 & & & & \\
\hline
\end{tabular}


Table 3 OLS Regression of $R_{k}$ on Stock and Market Related Factors $(N=5,040)$

\begin{tabular}{|c|c|c|c|c|c|c|c|c|}
\hline Model: & $\begin{array}{c}\text { BWW } \\
(\mathrm{N}=3,465)\end{array}$ & $\begin{array}{c}\text { Model } \\
1 \\
\end{array}$ & $\begin{array}{c}\text { Model } \\
2 \\
\end{array}$ & $\begin{array}{c}\text { Model } \\
3 \\
\end{array}$ & $\begin{array}{c}\text { Model } \\
4 \\
\end{array}$ & $\begin{array}{c}\text { Model } \\
5 \\
\end{array}$ & $\begin{array}{c}\text { Model } \\
6 \\
\end{array}$ & $\begin{array}{c}\text { Model } \\
7\end{array}$ \\
\hline Intercept & $15.20 * *$ & $57.53 * * *$ & 23.22 & 26.86 & 15.89 & 22.83 & 23.64 & 10.98 \\
\hline \multicolumn{9}{|l|}{ Stock: } \\
\hline $\mathrm{PP}_{\text {stk }}$ & $0.50^{* * *}$ & $0.38^{* * *}$ & $0.37^{* * *}$ & $0.38 * * *$ & $0.35 * * *$ & $0.37 * * *$ & $0.37^{* * *}$ & $0.35^{* * *}$ \\
\hline $\mathrm{CP}_{\text {stk }}$ & $0.27^{* * *}$ & $0.43^{* * *}$ & $0.45^{* * *}$ & $0.43^{* * *}$ & $0.50^{* * *}$ & $0.45^{* * *}$ & $0.45^{* * *}$ & $0.47^{* * *}$ \\
\hline $\mathrm{AIP}_{s t k}$ & $0.13^{* * *}$ & 0.02 & 0.03 & $0.06^{*}$ & 0.04 & $0.03 *$ & 0.03 & $0.07 *$ \\
\hline $\mathrm{HP}_{s t k}$ & $0.07^{* * *}$ & 0.00 & $0.02 *$ & 0.01 & 0.02 & 0.02 & 0.02 & 0.03 \\
\hline $\mathrm{LP}_{s t k}$ & $-0.04^{*}$ & $-0.05^{*}$ & $-0.06^{*}$ & $-0.06^{*}$ & $-0.06 * *$ & $-0.06^{*}$ & $-0.05^{*}$ & $-0.05^{*}$ \\
\hline LASTLEG $_{s t k}$ & - & - & - & $0.03 *$ & - & - & - & - \\
\hline TREND $_{s t k}$ & - & - & - & - & -0.10 & - & - & - \\
\hline \multicolumn{9}{|l|}{ Market: } \\
\hline $\mathrm{PP}_{m k t}$ & - & - & 0.05 & 0.04 & 0.03 & 0.05 & 0.05 & 0.06 \\
\hline $\mathrm{CP}_{m k t}$ & - & - & $0.06^{* * *}$ & 0.02 & $0.08^{* * *}$ & $0.06^{* * *}$ & $0.06^{* * *}$ & 0.02 \\
\hline $\mathrm{AIP}_{m k t}$ & - & - & $-0.05^{* *}$ & -0.02 & $-0.06^{* * *}$ & $-0.05^{* *}$ & $-0.05^{* *}$ & $-0.03^{*}$ \\
\hline $\mathrm{HP}_{m k t}$ & - & - & -0.01 & 0.01 & 0.00 & 0.00 & -0.01 & 0.00 \\
\hline $\mathrm{LP}_{m k t}$ & - & - & 0.01 & 0.00 & 0.02 & 0.01 & 0.02 & 0.02 \\
\hline LASTLEG $_{m k t}$ & - & - & - & $0.03^{* * *}$ & - & - & - & $0.03^{* * *}$ \\
\hline TREND $_{m k t}$ & - & - & - & - & $-0.13^{* * *}$ & - & - & - \\
\hline \multicolumn{9}{|l|}{ Covariation: } \\
\hline BETA & - & - & - & - & - & -0.30 & - & -0.13 \\
\hline TRACKERR & - & - & - & - & - & - & $0.05 *$ & - \\
\hline $\mathrm{BETA} \times$ LASTLEG $_{m k t}$ & - & - & - & - & - & - & - & $0.02 * * *$ \\
\hline Model LR Chi-square ${ }^{\dagger}$ & n.a. & $1,595^{* * *}$ & $1,662 * * *$ & $1,683^{* * *}$ & $1,672 * * *$ & $1,663^{* * *}$ & $1,665^{* * *}$ & $1,702 * * *$ \\
\hline degrees of freedom & n.a. & 5 & 10 & 12 & 12 & 11 & 11 & 13 \\
\hline \multicolumn{9}{|c|}{$\begin{array}{l}\text { Significance levels: }{ }^{* * *} .001,{ }^{* *} .01, \\
\text { tLikelihood ratio test of model fit }\end{array}$} \\
\hline
\end{tabular}


Table 4 OLS Regressions of $R_{k}$ on Partitioned Subsets

Model 1: All Stock Factors

Model 2: Final Model

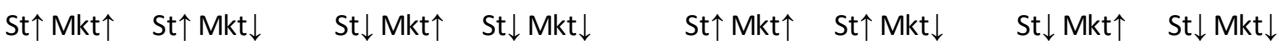

Panel $\boldsymbol{a}$. Partitions based on the sign of stock gain $\left(C P_{s t k}-P P_{s t k}\right)$ and market gain $\left(C P_{m k t}-P P_{m k t}\right)$.

$\begin{array}{rcccccccc}\text { Intercept } & 20.06 & 72.36^{* *} & 86.20^{* * *} & 110.81^{* * *} & 53.83^{* * *} & 25.75^{* *} & 55.08^{* * *} & 123.22^{* * *} \\ \mathrm{PP}_{\text {stk }} & -0.05 & 0.25 & 0.44^{* * *} & 0.14 & - & - & 0.45^{* * *} & - \\ \mathrm{CP}_{\text {stk }} & 1.04^{* * *} & 0.51^{* *} & 0.22^{*} & 0.60^{* * *} & 0.89^{* * *} & 0.85^{* * *} & 0.36^{* * *} & 0.72^{* * *} \\ \mathrm{AlP}_{\text {stk }} & 0.12 & -0.11 & -0.25^{*} & -0.16^{*} & - & - & - & -0.19^{* * *} \\ \mathrm{HP}_{\text {stk }} & -0.05 & -0.01 & 0.16^{\wedge} & 0.04 & - & - & - & - \\ \mathrm{LP}_{\text {stk }} & -0.28^{* * *} & 0.07 & 0.05 & -0.08 & -0.21^{* * *} & - & - & - \\ \mathrm{N} & 882 & 882 & 1008 & 1008 & 882 & 882 & 1008 & 1008 \\ \mathrm{LR} \text { Chi-sqr } & 218^{* * *} & 274^{* * *} & 348^{* * *} & 395^{* * *} & 217^{* * *} & 271^{* * *} & 341^{* * *} & 392^{* * *} \\ \mathrm{df} & 5 & 5 & 5 & 5 & 2 & 1 & 2 & 2\end{array}$

Panel $\boldsymbol{b}$. Partitions based on sign of stock trend $\left(\operatorname{TREND}_{s t k}\right)$ and market trend $\left(\operatorname{TREND}_{m k t}\right)$.

$\begin{array}{rcccccccc}\text { Intercept } & 38.93^{*} & 76.17^{* * *} & 14.74^{* *} & 62.86^{* * *} & 63.56^{* * *} & 94.40^{* * *} & 42.30^{* * *} & 72.77^{* * *} \\ \mathrm{PP}_{s t k} & 0.27^{* * *} & 0.45^{* * *} & 0.46^{* * *} & 0.29 * * * & 0.28^{* * *} & 0.44^{* * *} & 0.45^{* * *} & 0.29^{* * *} \\ \mathrm{CP}_{s t k} & 0.59^{* * *} & 0.38^{* * *} & 0.43^{* * *} & 0.51^{* * *} & 0.57^{* * *} & 0.38^{* * *} & 0.42^{* * *} & 0.52^{* * *} \\ \mathrm{AIP}_{s t k} & 0.06 & 0.06 & 0.07 & 0.00 & - & - & - & - \\ \mathrm{HP}_{s t k} & 0.06 & -0.17^{* *} & 0.05 & 0.05 & - & -0.16^{* * *} & - & - \\ \mathrm{LP}_{s t k} & -0.15^{* *} & 0.05 & -0.02 & -0.12^{*} & -0.14^{* * *} & - & - & -0.12^{* * *} \\ \mathrm{~N} & 1260 & 1008 & 1134 & 1134 & 1260 & 1008 & 1134 & 1134 \\ \mathrm{LR} \text { Chi-sqr } & 457^{* * *} & 301^{* * *} & 374^{* * *} & 339^{* * *} & 455^{* * *} & 300^{* * *} & 372^{* * *} & 339^{* * *} \\ \mathrm{df} & 5 & 5 & 5 & 5 & 3 & 3 & 2 & 3\end{array}$

Panel c. Partitions based on sign of stock gain $\left(C P_{s t k}-P P_{s t k}\right)$ and market trend (TREND $\left.m k t\right)$.

\begin{tabular}{rcccccccc} 
Intercept & -38.38 & $126.84^{* * *}$ & $49.86^{\wedge}$ & $105.67^{* * *}$ & $45.01^{* * *}$ & $86.45^{* * *}$ & $41.54^{* * *}$ & $81.46^{* * *}$ \\
$\mathrm{PP}_{s t k}$ & -0.20 & $0.41^{* *}$ & $0.49^{* * *}$ & 0.01 & - & $0.37^{* * *}$ & $0.47^{* * *}$ & - \\
$\mathrm{CP}_{s t k}$ & $1.32^{* * *}$ & $0.28^{\wedge}$ & $0.29^{*}$ & $0.75^{* * *}$ & $0.91^{* * *}$ & $0.48^{* * *}$ & $0.40^{* * *}$ & $0.84^{* * *}$ \\
$\mathrm{AIP}_{s t k}$ & $0.26^{*}$ & $-0.19^{\wedge}$ & -0.13 & $-0.15^{* *}$ & - & - & - & - \\
$\mathrm{HP}_{s t k}$ & 0.00 & $-0.12^{\wedge}$ & 0.12 & 0.06 & - & $-0.17^{* * *}$ & - & - \\
$\mathrm{LP}_{s t k}$ & $-0.35^{* * *}$ & $0.14^{\wedge}$ & 0.03 & -0.08 & $-0.19^{* * *}$ & - & - & $-0.12^{*}$ \\
$\mathrm{~N}$ & 819 & 693 & 882 & 882 & 819 & 693 & 882 & 882 \\
$\mathrm{LR}$ Chi-sqr & $232^{* * *}$ & $211^{* * *}$ & $343^{* * *}$ & $334^{* * *}$ & $228^{* * *}$ & $209^{* * *}$ & $341^{* * *}$ & $335^{* * *}$ \\
$\mathrm{df}$ & 5 & 5 & 5 & 5 & 2 & 3 & 2 & 2 \\
\hline
\end{tabular}

Significance levels: ***.001, **.01,*.05, ^.10

Note: Standard errors are clustered by subject.

Note: For TREND variable, partitions consist of top and bottom tercile. 
Figure 1. Illustration of Reference Point Adaptation in Gain versus Loss Domain

Reference point adaptation, measured by $A_{i}=\left(R_{i}-P P\right) /(C P-P P)$ for individual $i$, is illustrated for selected price paths. Complete adaptation is defined as $A_{i}=1$.

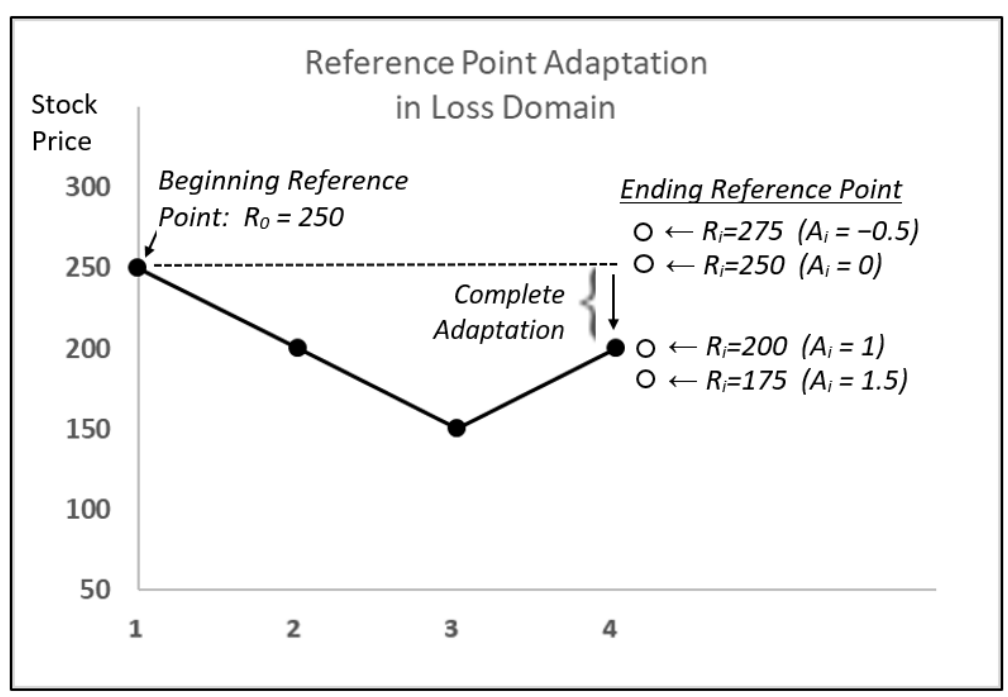

\section{Panel a. Loss Domain (CP < PP)}

This panel corresponds to price path 1 (used for cases $1 a-1 d$ ). Note that in the loss domain, positive (negative) adaptation corresponds to a decrease (increase) in the reference point.

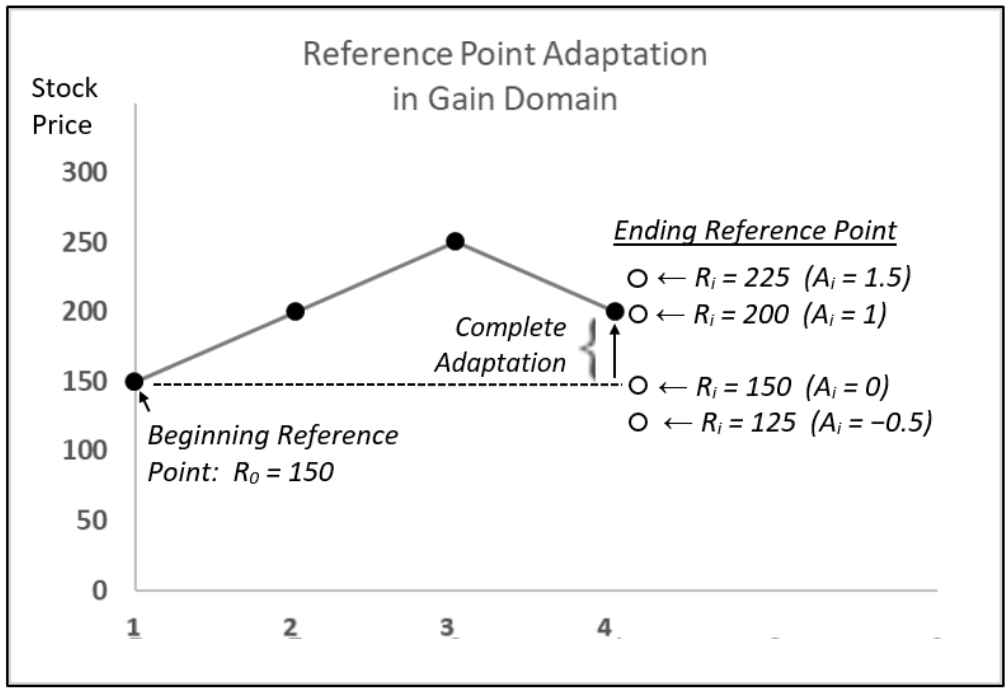

Panel b. Gain Domain (CP > PP)

This panel corresponds to price path 2 (used for cases $2 a-2 d$ ). Note that in the gain domain, positive (negative) adaptation corresponds to an increase (decrease) in the reference point. 


\section{Figure 2. Interaction Between Stock and Market Effects}

Panels $a$ and $b$ illustrate the interaction between stock and market influences. Each panel compares reference point adaptation between two selected stock patterns, in this case patterns 1 and 2 as defined by Table 1; these patterns are denoted by subscripts $j$ and $k$, respectively. The pairs are designed to isolate the impact of purchase price. The patterns in each pair are identical with regard to four of the five price factors (CP, AIP, HP, LP), but differ in purchase price. By comparing the difference between mean reference prices averaged across subjects for patterns $j$ and $k$, we can measure the impact of purchase price while holding other factors constant. Panels $a$ and $b$ measure the comparative impact under different market backgrounds. In panel $a$ the market follows a down-up pattern; whereas in panel $b$ it follows an up-down pattern. Panels $a$ and $b$ provide an example of calculations used to construct Table 2.
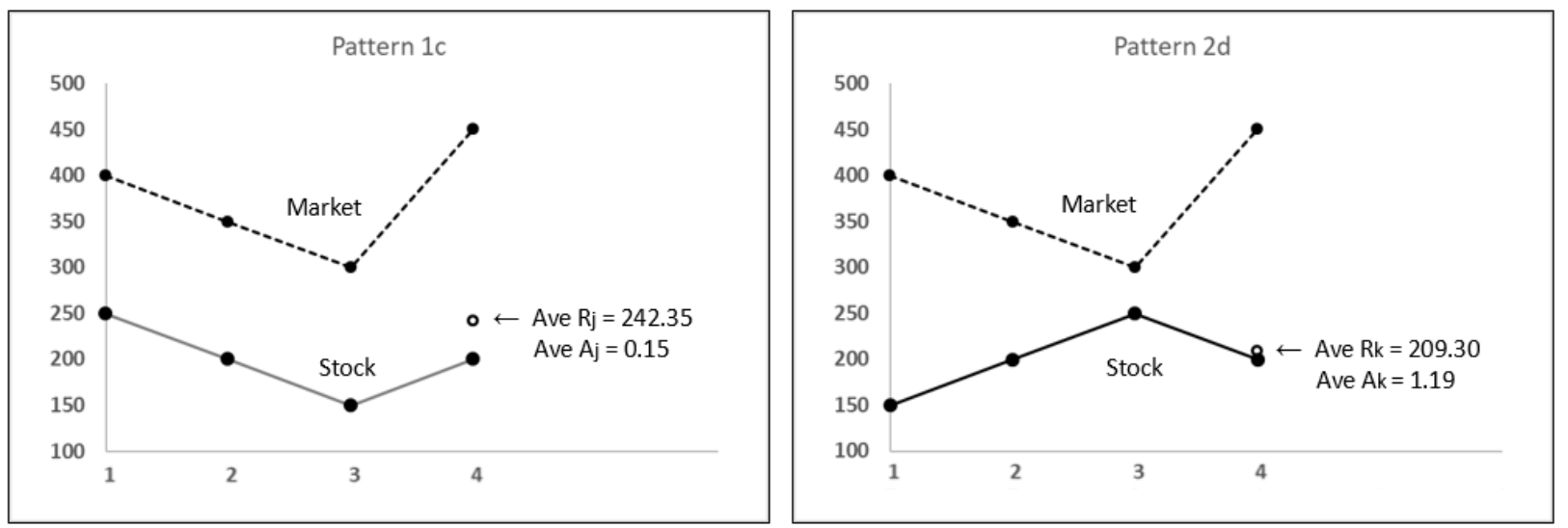

Panel $a$. Pattern $1 c$ versus $2 d$.

This panel compares stock patterns 1 and 2 where the market follows a down-up pattern. The difference in average reference point across all subjects is $\left(R_{j}-R_{k}\right)=(242.35-209.30)=33.05$, whereas the difference in purchase price is $\left(P P_{j}-P P_{k}\right)=(250-150)=100$. The unit effect can be measured as 33.05/100 =0.3305. This analysis corresponds to line 3 in Table 2.
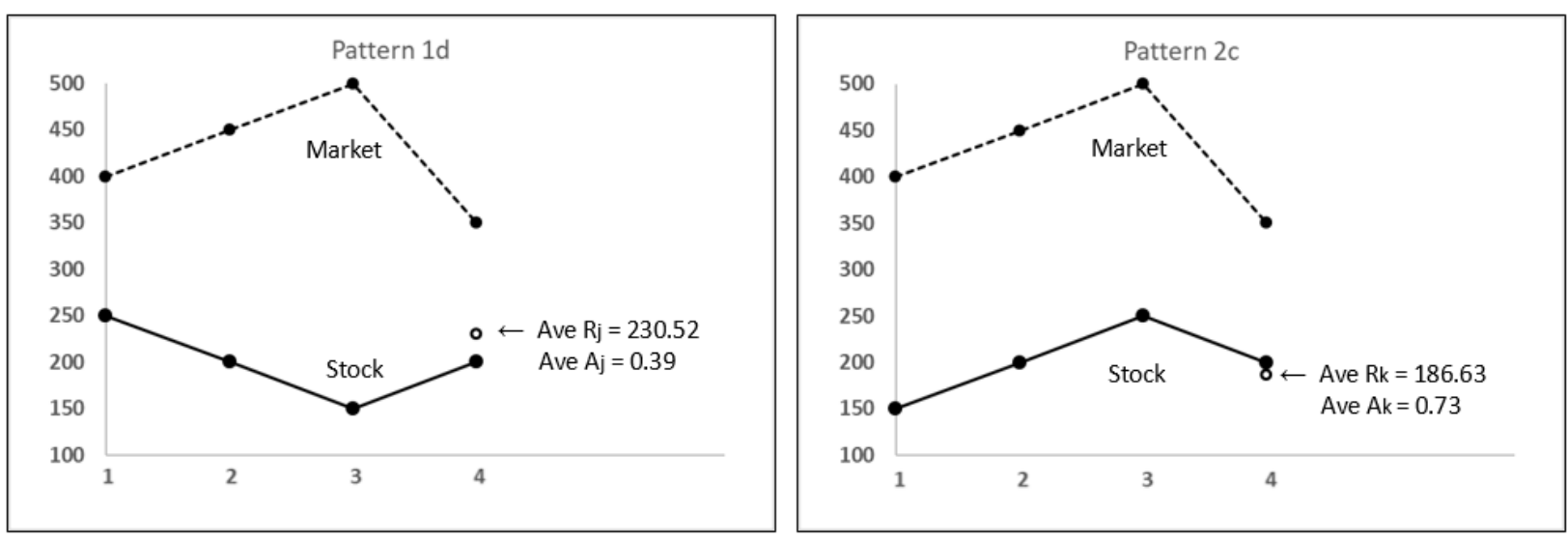

Panel $b$. Pattern 1d versus $2 c$.

This panel compares stock patterns 1 and 2 where the market follows a down-up pattern. The difference in average reference point across all subjects is $\left(R_{j}-R_{k}\right)=(230.52-186.63)=43.89$, whereas the difference in purchase price is $\left(P P_{j}-P P_{k}\right)=(250-150)=100$. The unit effect can be measured as $43.89 / 100=0.4389$. This analysis corresponds to line 4 in Table 2. 


\section{Figure 3. Average Reference Point Adaptation in Gain versus Loss Domain ( $n=63$ subjects)}

Each point represents a given subject's combination of average reference point adaptation $\left(A_{k}\right)$ in stock gain scenarios ( $y$-axis) and stock loss scenarios ( $x$-axis). Subjects who plot above the 45-degree diagonal exhibit a disposition effect where adaptation is more complete for gains than for losses; whereas subjects who plot below the diagonal exhibit a 'reverse' disposition effect where adaptation is more complete for losses than for gains. Stock gains and losses are defined by the sign of $\left(C P_{s t k}-P P_{s t k}\right)$. Results are segregated into down-market scenarios (panel $a$ ) and up-market scenarios (panel $b$ ), where up and down markets are defined by the sign of LASTLEG_mkt. Reference point adaptation is measured by $A_{k}=\left(R_{k}-P P\right) /(C P-P P)$ for individual $k$.

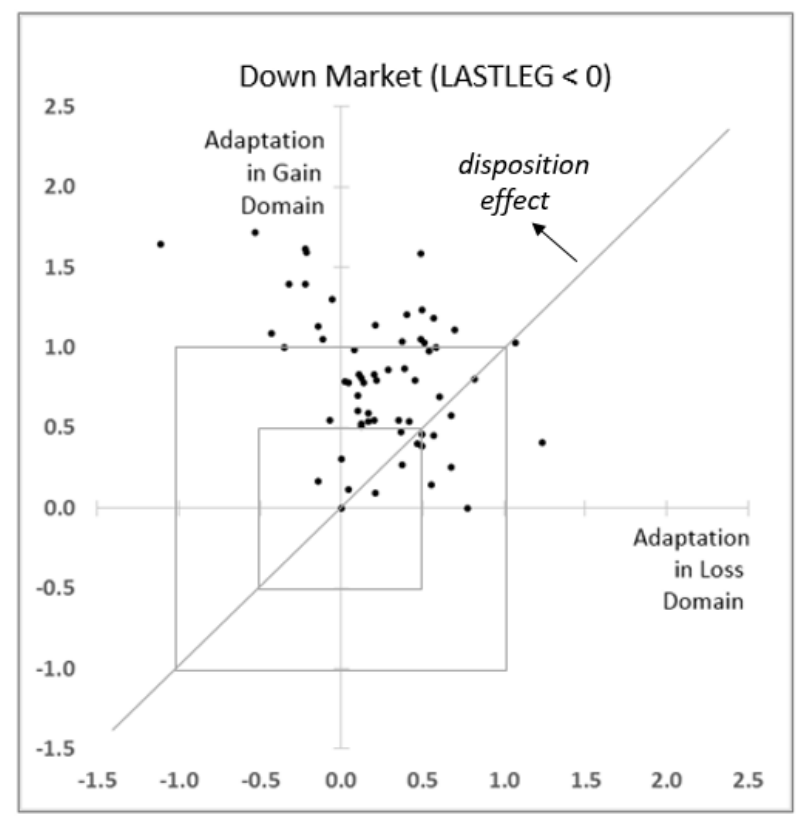

Panel $a$. Adaptation in down market.

In down-market scenarios, 49 subjects (78\%) exhibited a disposition effect and 13 subjects (21\%) exhibited a 'reverse' disposition effect. The average adaptation was $A_{k}=0.82$ in the gain domain and $A_{k}=0.22$ in the loss domain.

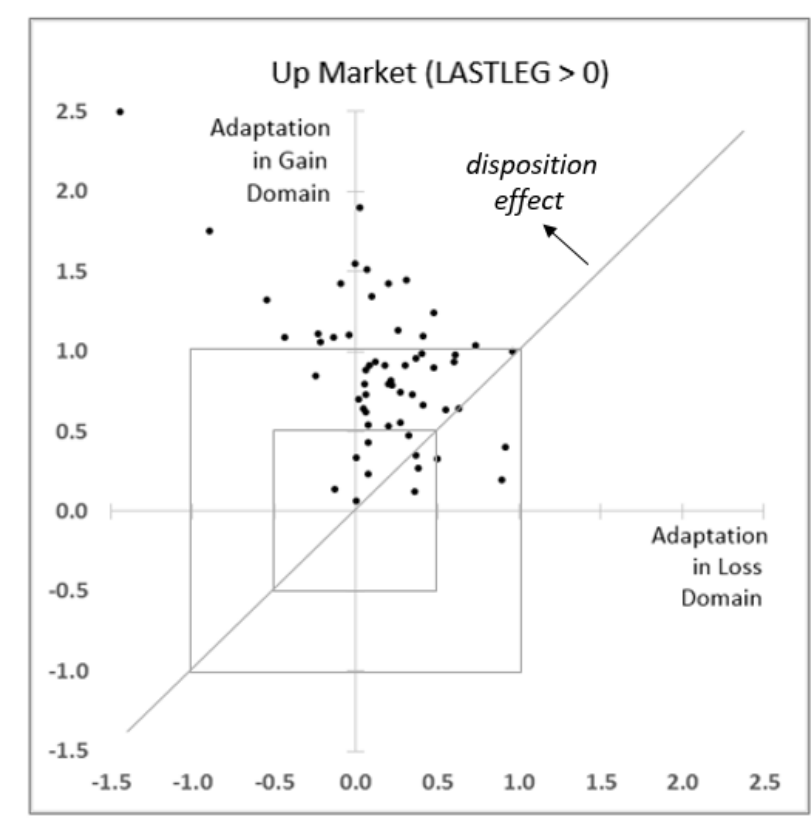

Panel $b$. Adaptation in up market.

In up-market scenarios, 57 subjects (90\%) exhibited a disposition effect and 6 subjects (10\%) exhibited a 'reverse' disposition effect. The average adaptation was $A_{k}=0.95$ in the gain domain and $A_{k}=0.13$ in the loss domain. 


\section{Figure 4. Average Reference Point Adaptation in Up versus Down Market ( $n=63$ subjects)}

Each point represents a given subject's combination of average reference point adaptation $\left(A_{k}\right)$ in up-market scenarios ( $y$-axis) and down-market scenarios ( $x$-axis). Subjects who plot above the 45-degree diagonal adapted their reference point more completely in up markets relative to their adaptation in down markets; subjects who plot below the diagonal adapted their reference point more completely in down markets relative to up markets. Up and down markets are defined by the sign of LASTLEG_mkt. Results are partitioned into stock loss scenarios (panel $a$ ) and stock gain scenarios (panel $b$ ), where stock gains and losses are defined by the sign of $\left(C P_{s t k}-P P_{s t k}\right)$.

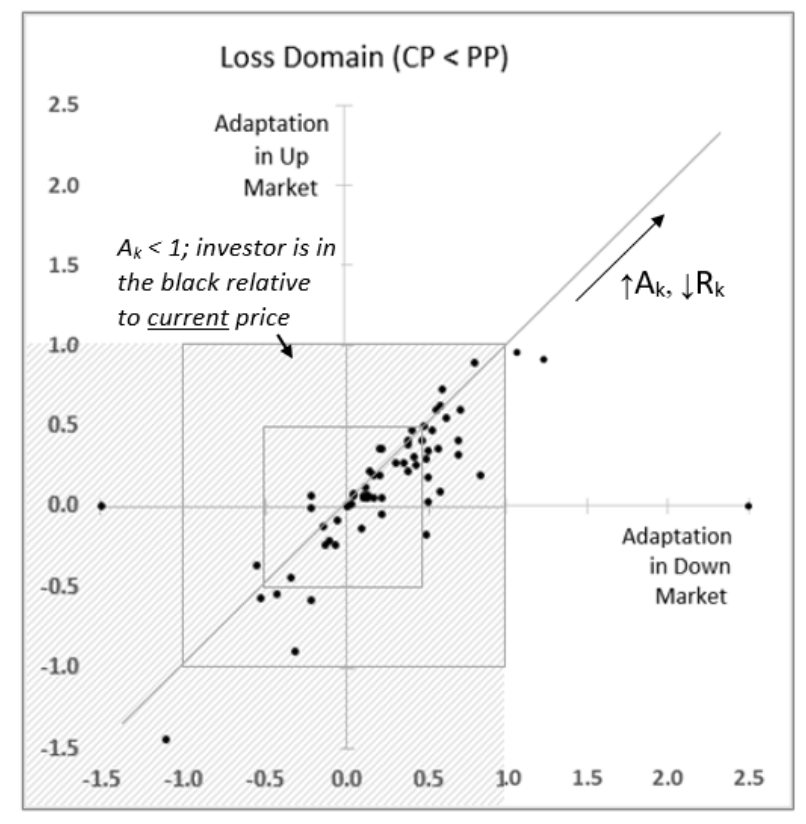

Panel a. Adaptation in Loss Domain.

Positive (negative) adaptation corresponds to a decrease (increase) in the reference price. The shaded area indicates where the investor is in the black relative to the stock's current price in both up and down markets. In the loss domain, 41 subjects (65\%) exhibited greater adaptation in down versus up markets; whereas only 20 subjects (32\%) adapted more completely in up versus down markets. The average adaptation was $A_{k}=0.13$ in up markets and $A_{k}=0.22$ in down markets.

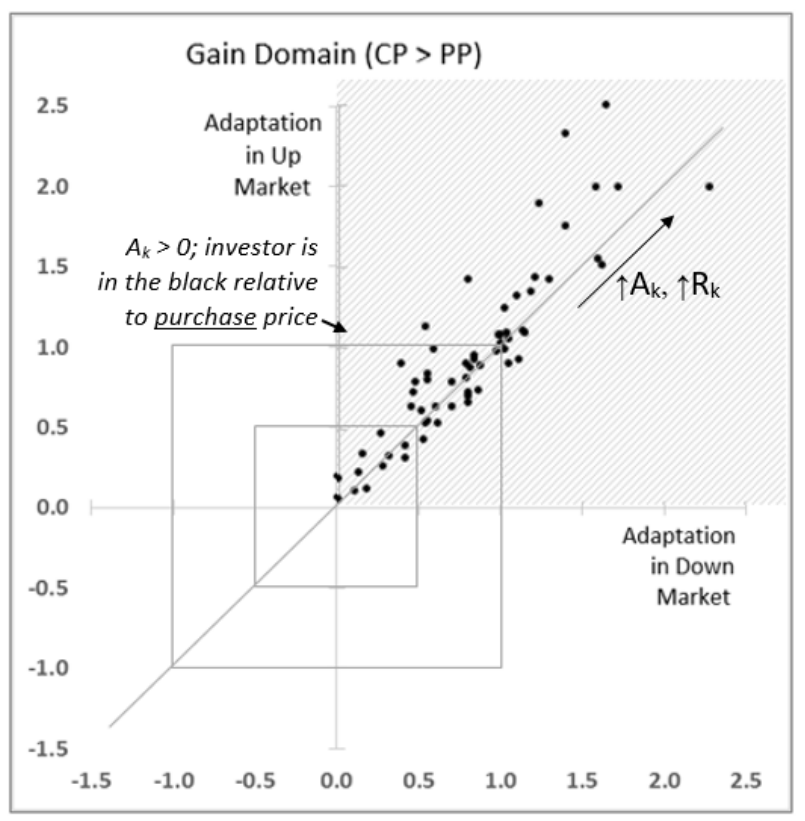

Panel $b$. Adaptation in Gain Domain.

Positive (negative) adaptation corresponds to an increase (decrease) in the reference price. The shaded area indicates where the investor is in the black relative to the stock's purchase price in both up and down markets. In the gain domain, 43 subjects (68\%) exhibited greater adaptation in up versus down markets; whereas only 20 subjects (32\%) adapted more completely in down versus up markets. The average adaptation was $A_{k}=0.95$ in up markets and $A_{k}=0.82$ in down markets. 
Figure 5. Impact of Beta and on Reference Point Adaptation: GAIN domain

Panels $a$ and $b$ summarize the expected marginal effect of beta and economic state on reference point adaptation and on the characteristic line of the graphs from figure 4.

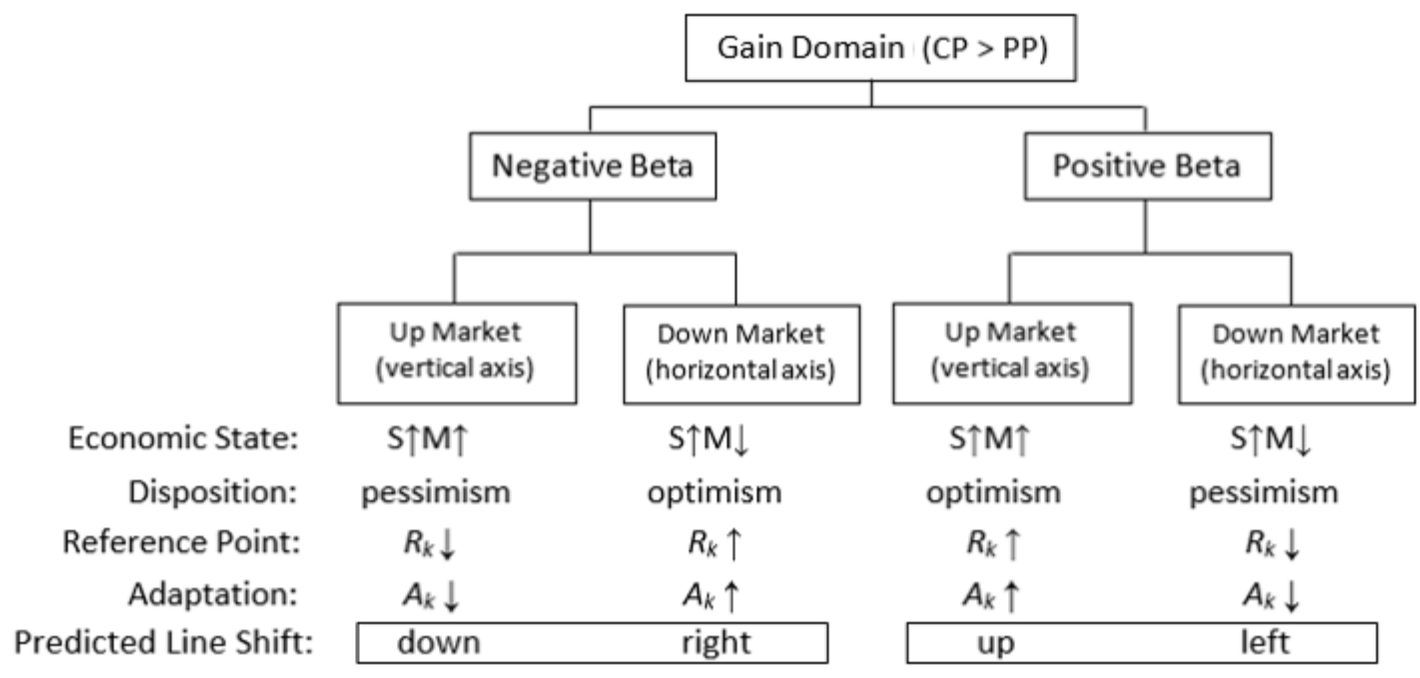

Panel a. Hypothesized Shift of Characteristic Line in GAIN domain: Negative versus Positive Beta. Expected impact of beta on reference point adaptation, where market direction is measured by LASTLEG. We hypothesize that for negative (positive) beta, the characteristic line will tend to situate relatively down (up) and to the right (left).
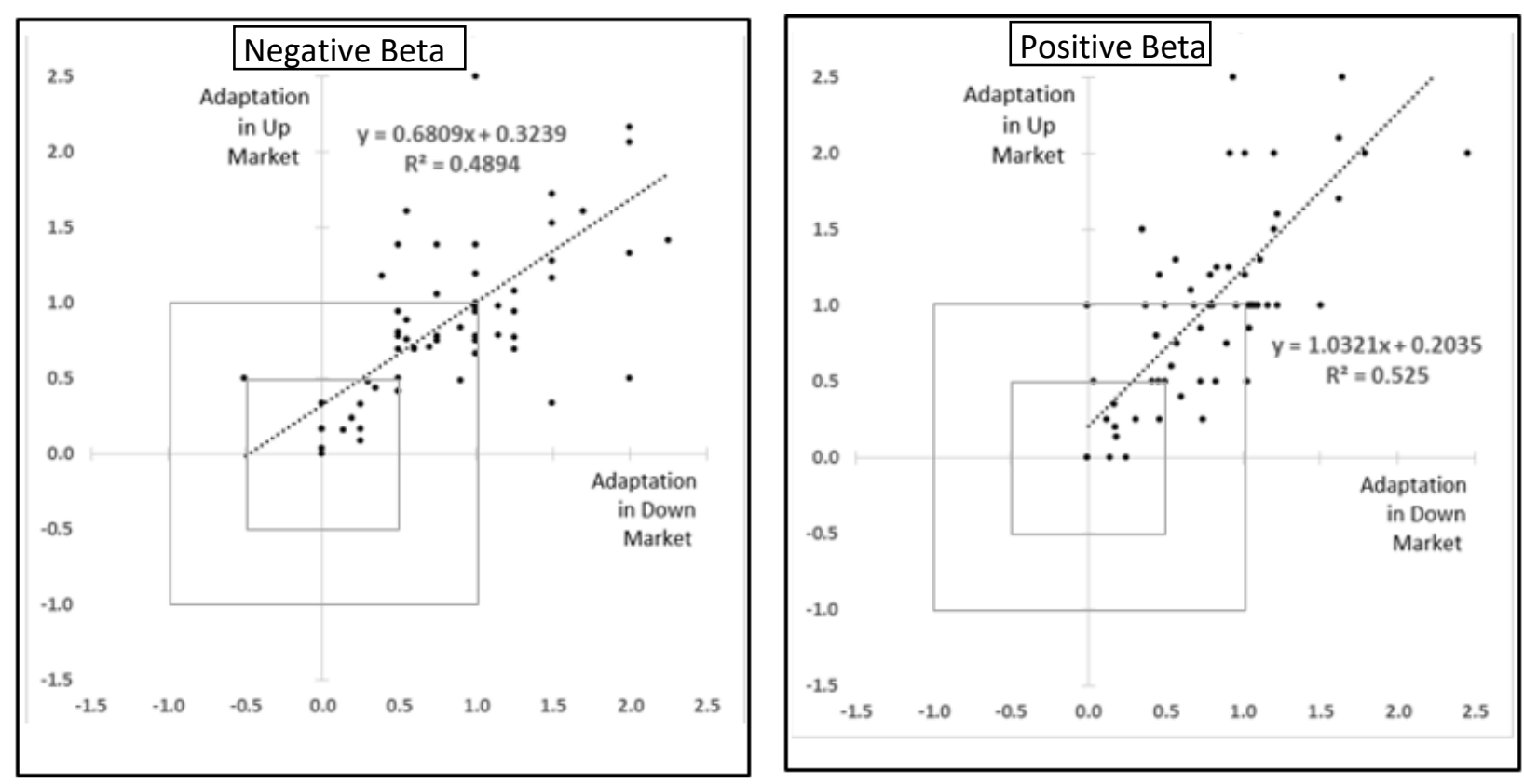

Panel $b$. Observed Shift of Characteristic Line in GAIN domain: Negative versus Positive Beta. Observed reference point adaptation for positive and negative beta, defined by top and bottom tercile, respectively, using cutoff values of \pm 1.15 . Top and bottom terciles each contain 27 price sequences. 
Figure 6. Impact of Beta and on Reference Point Adaptation: LOSS domain

Panels $a$ and $b$ summarize the expected marginal effect of beta and economic state on reference point adaptation and on the characteristic line of the graphs from figure 4.

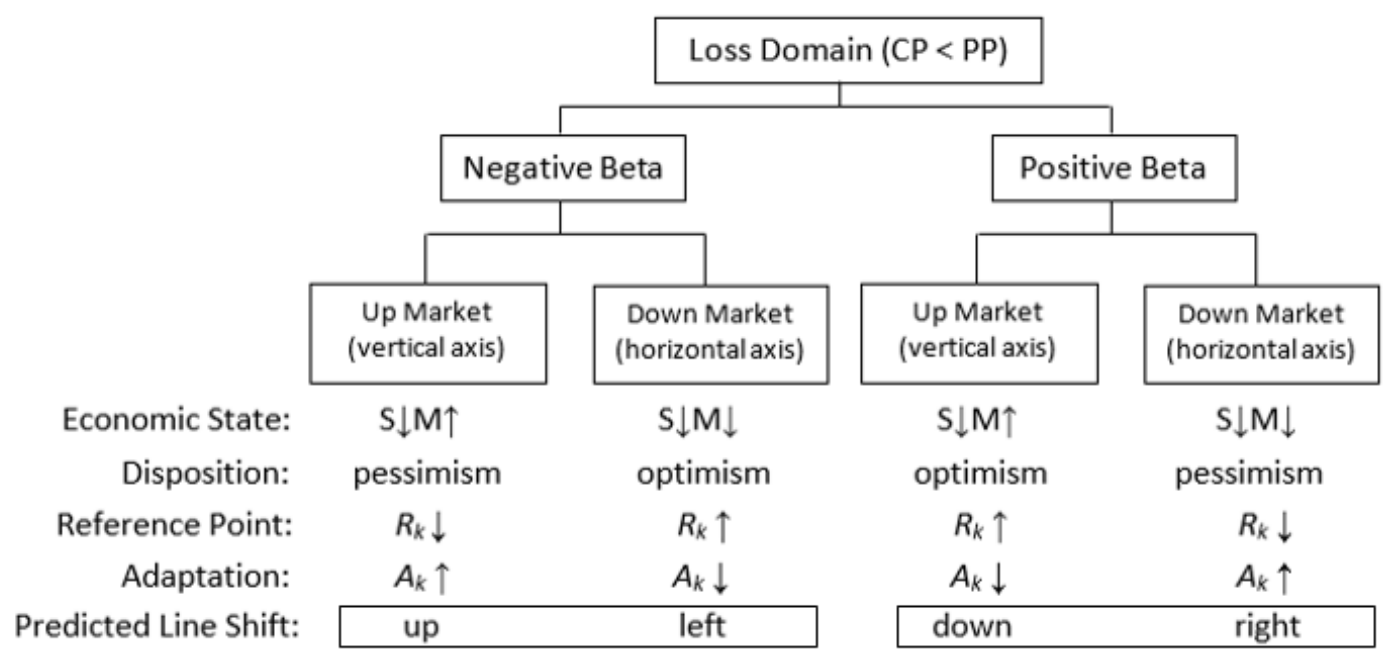

Panel a. Hypothesized Shift of Characteristic Line in LOSS domain: Negative versus Positive Beta.

Expected impact of beta on reference point adaptation, where market direction is measured by LASTLEG. We hypothesize that for negative (positive) beta, the characteristic line will tend to situate relatively up (down) and to the left (right).
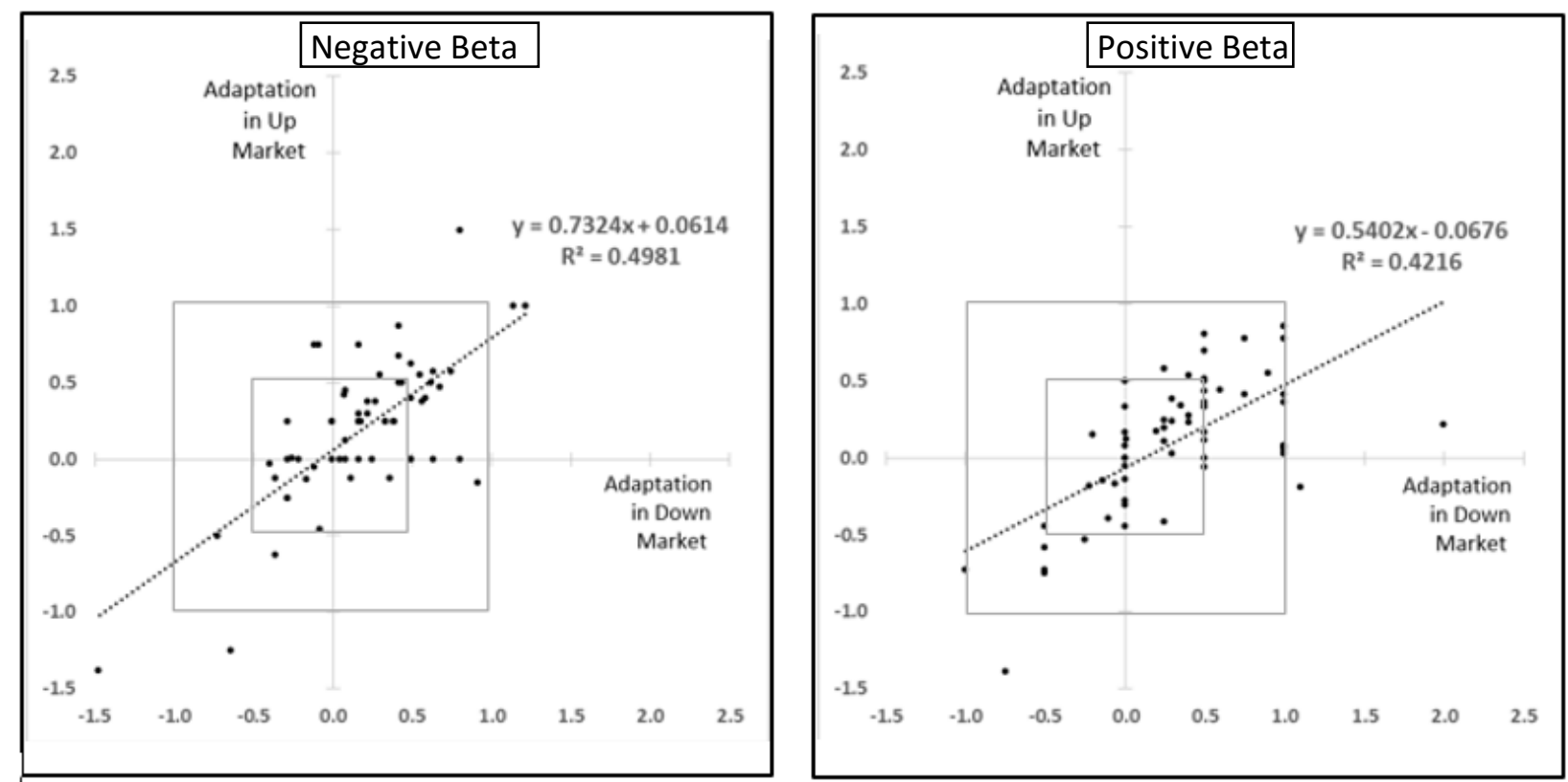

Panel $b$. Observed Shift of Characteristic Line in LOSS domain: Negative versus Positive Beta.

Observed reference point adaptation for positive and negative beta, defined by top and bottom tercile, respectively, using cutoff values of \pm 1.15 . Top and bottom terciles each contain 27 price sequences. 


\section{Figure 7. Characteristic Lines for BETA Terciles}

Panels $a$ and $b$ summarize the characteristic lines, determined as in figures 5 and 6 , for BETA terciles. Terciles are determined by cutoff values of \pm 1.15 .

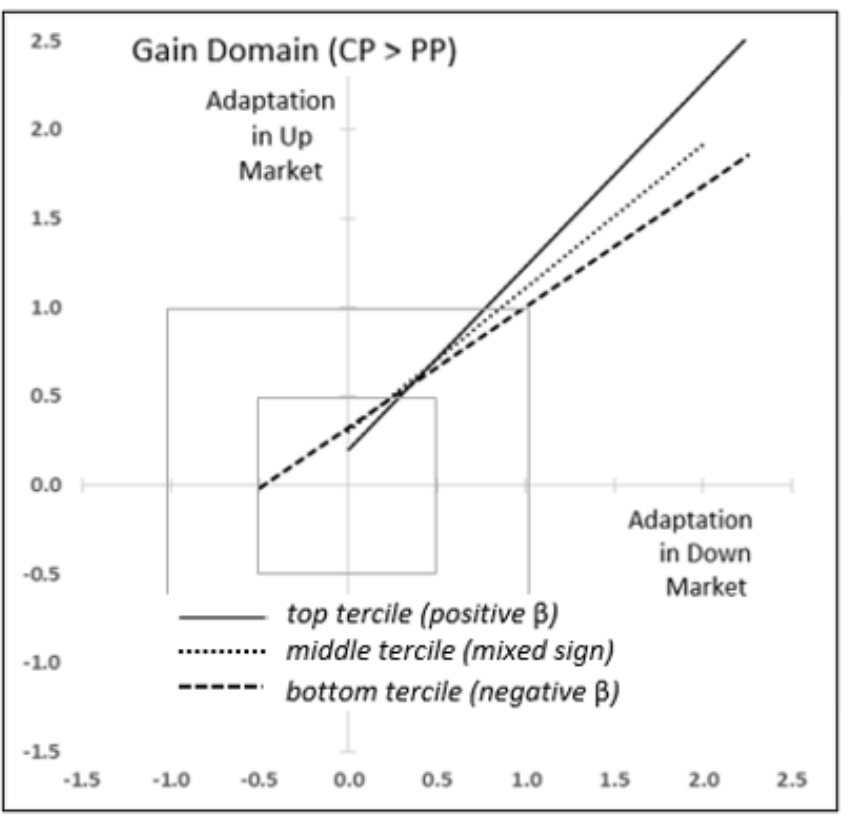

Panel a. GAIN Domain.

Observed characteristic lines for partitions based on beta terciles using cutoff values of \pm 1.15 . It is hypothesized that in the GAIN domain, the negative partition (bottom tercile) should situate relatively down and to the right.

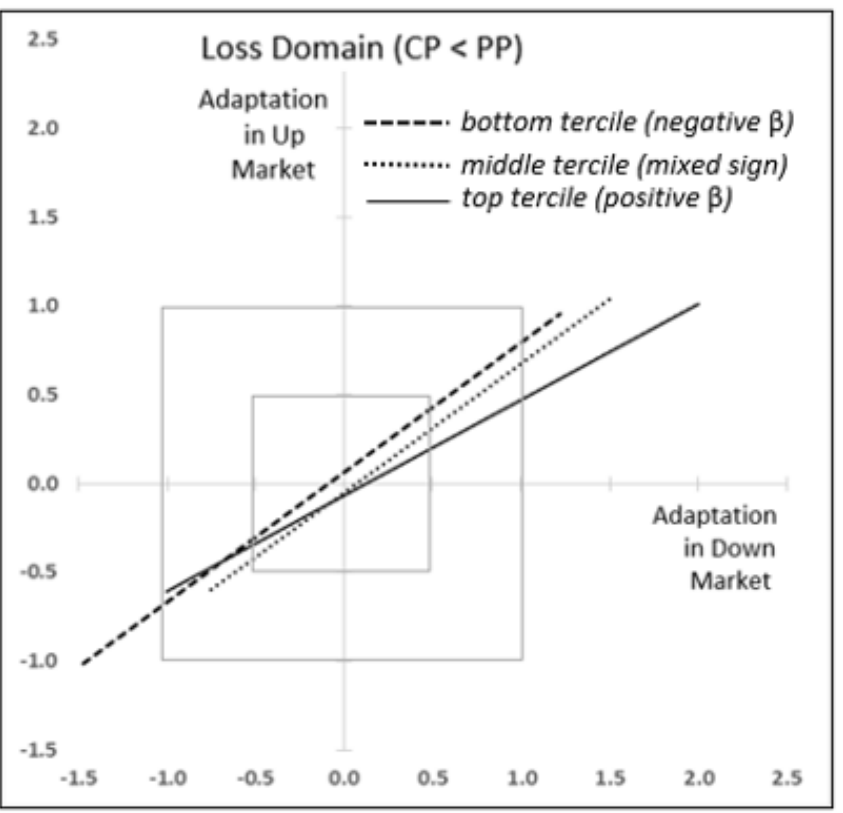

Panel $b$. LOSS Domain.

Observed characteristic lines for partitions based on beta terciles using cutoff values of \pm 1 .15. It is hypothesized that in the LOSS domain, the negative partition (bottom tercile) should situate relatively up and to the left. 